\title{
Natural Coral as a Biomaterial Revisited
}

\author{
LH Yahia ${ }^{1 *}$, G Bayade $^{1}$ and Y Cirotteau ${ }^{2}$ \\ ${ }^{1}$ LIAB, Biomedical Engineering Institute, Polytechnique Montreal, Canada \\ ${ }^{2}$ Neuilly Sur Seine, France
}

*Corresponding author: LH Yahia, LIAB, Biomedical Engineering Institute, Polytechnique Montreal, Canada

To Cite This Article: LH Yahia, G Bayade, Y Cirotteau. Natural Coral as a Biomaterial Revisited. Am J Biomed Sci \& Res. 2021 - 13(6). AJBSR. MS.ID.001936. DOI: 10.34297/AJBSR.2021.13.001936.

Received: 眥 July 07, 2021; Published: 酸 August 18, 2021

\begin{abstract}
This paper first describes the state of the art of natural coral. The biocompatibility of different coral species has been reviewed and it has been consistently observed that apart from an initial transient inflammation, the coral shows no signs of intolerance in the short, medium, and long term. Immune rejection of coral implants was not found in any tissue examined. Other studies have shown that coral does not cause uncontrolled calcification of soft tissue and those implants placed under the periosteum are constantly resorbed and replaced by autogenous bone. The available studies show that the coral is not cytotoxic and that it allows cell growth. Thirdly, porosity and gradient of porosity in ceramics is explained based on far from equilibrium thermodynamics. It is known that the bone cross-section from cancellous to cortical bone is non-uniform in porosity and in pore size. Thus, it is hypothesized that a damaged bone containing both cancellous and cortical bone can be better replaced by a graded/gradient porous implant based on the idea of a biomimetic approach. The purpose of this article is to review and summarize all the pertinent work that has been published on natural coral as a bone graft during the last twenty years including in vitro, animal, and clinical human studies. In addition, as an illustration, we report the clinical experience of one of us using coral. It is a case study of complex femoral fracture (Table 1) where the essential role of vascularization and stabilization of the fracture site are underlined. The results are supported with more than 300 other femoral fractures treated using the same modus operandi. Finally, this paper overviews the ecological and ethical concerns around the use of corals as well as discussing briefly about recent impacts of nano-pollutants.
\end{abstract}

\begin{tabular}{|c|c|}
\hline Pre-op $t=0$ month & The femoral fracture is located in the lower half of the femur. The hearth has 4 large fragments and a few small shards. \\
\hline $\mathrm{t}=7$ Months & $\begin{array}{l}\text { The reduction of the focal point is very approximate. The osteosynthesis by platelets persists an axial deviation and a } \\
\text { stable inter-fragmentary gap prevents consolidation. }\end{array}$ \\
\hline Post-op t = D0 + 1 & $\begin{array}{l}\text { The recovery restores the diaphyseal axis and anatomically restores the diaphysis. The coral graft is distributed in } \\
\text { contact with the shelled femoral sleeve. }\end{array}$ \\
\hline $\mathrm{t}=3$ months & $\begin{array}{l}\text { The spheres are no longer visible on a visual scale and an inhomogeneous bone callus surrounds the focal point of the } \\
\text { fracture. }\end{array}$ \\
\hline $\mathrm{t}=4$ months & $\begin{array}{l}\text { The ends are joined. The diaphysis is reconstructed. The callus is hypertrophic, and the spinal canal is dense on the } \\
\text { front X-ray. }\end{array}$ \\
\hline $\mathrm{t}=20$ months & The diaphysis is anatomically reconstructed. The medullary canal is permeable. \\
\hline
\end{tabular}

Keywords: Femur Fracture, Non-Union, Graft, Bone Marrow, Natural Coral, Plate-Blade, Diaphyseal Vascularization.

Abbreviations: CoCr: Cobalt-Chrome; TGF- $\beta 1$ : Transforming Growth Factor Beta 1; NiTi: Nickel-Titanium; SHS: self-Propagating High-Temperature Synthesis; CS: Combustion Synthesis; SFF: Solid Freeform Fabrication; OWHTO: Opening Wedge High Tibial Osteotomy; CC: Calcium Carbonate

\section{Introduction}

The 3 main factors currently driving the world demand for biomaterials for medical use are the ageing world population with increasing incidences of diseases, such as osteoporosis and arthritis, where the efficacy of metal implants is greatly reduced and may even cause severe complications. Secondly, technological advances. The biomaterials now on the market have greatly enhanced qualities that aid the healing process and reduce the need for secondary surgeries. Thirdly, the growing increase in sporting and road trauma injuries. Bone grafting is the most common transplant procedure performed today. In the US alone surgeons perform more than 1 
million bone grafts annually to treat some 7 million fractures at a cost of $\$ 2.5$ billion. In the EU there are currently an estimated 22 million women and 5.5 million men aged between $50-84$ years old with osteoporosis and the rate of hip-related fractures will increase accordingly Esther, et al. [1]. Autologous bone grafting has all the properties of the ideal graft material, being an osteoinductive and osteoconductive scaffold with no immunogenicity and containing significant numbers of osteoprogenitor cells. However, its use has several drawbacks including limited availability, variable graft quality, surgery complications, increased operative time and donor site morbidity Giannoudis, et al. [2-4].

Ceramics are widely used for bone repair and bone regeneration in orthopedics and dentistry. From the end of the 1980s, our biomaterials laboratory at Polytechnique Montreal got involved in the development of alumina ceramic prostheses Boutin, et al. [5]. Boutin introduced alumina ceramics for hip prostheses in the early 1970s. Before this, metal was the femoral end (head/ ball) that was used. Unfortunately, the metal system usually failed because of wear based on Cobalt-Chrome ( $\mathrm{CoCr}$ ) grinding away at the polyethylene cup. Much of this was because the metal could only be polished to a certain level of smoothness. The failure was accompanied by a large amount of wear debris in the joint space. The result of this wear debris was characterized as particle disease. The use of polished alumina as part of the articulating joint was motivated mainly by its exceptionally low coefficient of friction and low wear rates Lerouge, et al. [6,7]. The superb tribology properties (friction and wear) of alumina occur only when the grains are very small $(<4 \mu \mathrm{m})$ and have a very narrow size distribution. These conditions lead to very low surface roughness values $(\mathrm{Ra}<0.02 \mu \mathrm{m})$. Subsequently, our group accompanied this development during a decade of collaboration with Professor Sedel's laboratory, until the approval of alumina prostheses by the FDA in 2003 Lerouge, et al. [6-9] In parallel, our laboratory hasalso been involved later in resorbable ceramics such as coral in the early 2000s Demers, et al. [10]. Coral bone graft substitutes have been supplemented in the past with growth factors to further enhance bone regeneration in defects. Little is known, however, on the dynamics of protein release from coral. Coral particles were studied for their ability to release transforming growth factor beta 1 (TGF- $\beta 1$ ) in vitro, under different adsorption conditions. Moreover, it was found that coral is biocompatible Petite [11]. Studies in our laboratory suggest that coral particles could be used as a delivery system for growth factors, and that the release rate may be modulated through modification of the adsorption conditions and coral particle size Demers, et al. [12]. In short, the purpose of this article is to review and summarize all the pertinent work that has been published on natural coral as a bone graft during the last twenty years including in vitro, animal, and clinical human studies. Furthermore, porosity and gradient of porosity in ceramics are explained based on far from equilibrium thermodynamics. In addition, the clinical experience of one of us is highlighted.

\section{State of the Art}

\section{Coral Materials}

Over the past decade, a new generation of biomimetic or bioinspired materials has been developed to provide biophysical and biochemical cues intended to bone tissue regeneration. Coral skeleton is one of the candidates often used as bone biomaterial or a source of inspiration for designing 3D bone scaffolds Ehrlich, et al. [13-17]. Moreover, as recently reported by Gancz and co-workers, "the coral skeleton biomaterial may act as a strong, promotive scaffold for tissue regeneration due to its ability to reduce its rejection by inflammatory reactions such as phagocytosis" Gancz et.al. [17]. Coral-derived material is biocompatible, structurally similar to human bone, with young's modulus of 0.580 to 9.032 GN $\mathrm{m}^{-2}$ Boller et al. [18], non-toxic, biodegradable and of low immunogenicity Ehrlich, et al. [19].

\section{Resorption and Neoformation Process}

The studies by Guillemin, et al. [20] show that the process of bone remodeling differs between a non-implanted bone lesion with a coral biomaterial and an implanted site. The process of regeneration of a bone lesion (in a dog tibia) without filling shows repair from the endosted edges of the bone lesion as well as from the periosteum according to a membranous model. So that for the coral skeleton we observe:

a) An invasion of the pores by the extravasated cellular elements of the marrow,

b) An osteoclastic resorption of the coral skeleton concomitant with an osteoblastic apposition,

c) Bone remodeling.

The appearance of osteoclasts at the bone-coral interface is observed early in the repair process. They remain present on histological sections until complete resorption of the coral implant (8 weeks) Guillemin, et al. [20] Regarding replacements, the evolution of sites without filling mainly results in pseudoosteoarthritis. The regeneration of sites implanted with a fragment of the coral skeleton is carried out according to the same process as the fillings but over a longer period: colonization of the biomaterial by the extravasated elements of the bone marrow, early vascularization followed by gradual resorption and gradual replacement of it by cancellous bone. Later, this spongy bone tissue resorbs at the medullary level and develops into compact bone at the cortical level. The appearance of cancellous bone is noted from the $6^{\text {th }}$ week and at 1 year. There are still a few rare islands of coral skeleton. Thus, it has been shown that the implanted coral gradually 
reabsorbs to give way to new bone tissue. This phenomenon appears to be dependent on the action of osteoclasts that are constantly found at the edges of implanted coral fragments. This action has been reported to the activity of the carbonic anhydrase they contain Gay, et al. [21,22] because the intervention of this enzyme in the destruction of carbonate substrates has already been demonstrated. Indeed, animal studies have showed that the injection of specific inhibitors (such as acetazolamide) of carbonic anhydrase resulted in a significant slowing resorption of the implanted coral, compared to the case not treated with this inhibitor. This slowing down was associated with bone necrosis at the edge of the implant, leading in all cases to pseudo-osteoarthritis. Carbonic anhydrase an enzyme that assists conversion of carbon dioxide and water into carbonic acid, protons, and bicarbonate ions - would play a role in within the osteoclast, the role of proton pump increasing the extracellular $\mathrm{pH}$ and promoting the dissolution of minerals.

\section{Biocompatibility}

The biocompatibility of coral in different species has been evaluated by different authors. It has been consistently observed that apart from an initial transient inflammation, the coral shows no signs of intolerance in the short, medium, and long term. None of the following reactions were reported: acute or chronic inflammation, infectious reaction with neutrophils, rejection reaction with proliferation of round cells, fibrous encapsulation. Immune rejection of coral implants was not found in any tissue examined. Other studies have shown that coral does not cause uncontrolled calcification of soft tissue and those implants placed under the periosteum are constantly resorbed and replaced by autogenous bone. Most in vitro studies have analyzed the biocompatibility between coral and osteoprogenitors. This support material should allow the attachment, proliferation, differentiation of MSCs and osteoblasts Tran, et al. [23]. The available studies show that the coral is not cytotoxic and that it allows cell growth Shamsuria, et al. [24].

When cells are placed on the coral granules, they show a good capacity for attachment, spreading and proliferation. Following osteogenic induction, alkaline phosphatase activity and the presence of mineral matrix have been observed in the coral material and their count were significantly higher in osteoblasts implanted in coral than in other ceramic materials. Analysis of gene expression osteoblasts implanted in Porites-like coral showed increased expression of RUNX 2, osteopontin, alkaline phosphatase and osteocalcin. The authors concluded that the coral is a favorable material for the implantation of osteogenic cells Lean, et al. [25]. Finally, a study comparing the implantation of osteogenic cells in a coral graft vs a human bone graft concluded that the osteogenic differentiation of MSCs is superior in a coral graft compared to a bone graft. An important and differentiating factor is the increased expression of osteonectin. We have tried to extend the properties of coral by adding osteoinductive molecules. Coral particles can absorb and diffuse TGF- $\beta 1$ in vitro Demers, et al. [10]. Another study shows that a chitosan/coral composite material was combined with a plasmid encoding the PDGF- $\beta$ protein. The proliferation of inseminated cells was increased.

\section{Porosity of Bone Biomaterials: Lessons from Bone and Natural Coral}

Most porous biomaterials developed and studied so far are homogeneous in terms of pore size distribution, porosity distribution, composition, and mechanical properties. However, bone cross-section from cancellous to cortical bone is known to be non-uniform in porosity and in pore size. Therefore, a graded/ gradient porous will mimic better the natural bone structure. During the last decades, several methods have been developed for the fabrication of graded/gradient porous biomaterials Miao, et al. $[26,27]$.

\section{Gradient of Porosity}

Gradients are largely present in the body leading several events and processes in the living organisms. Structural and composition gradients can be found in the body mainly at the interface between tissues. For example, a structural gradient is found in long bones in radial direction and in flat bones in axial direction, presenting a variation in bone density from the cancellous bone to the cortical bone Wang, et al. [28]. The architecture of bone is such that the resulting porosities are non-uniform in nature. Sobral, et al. [29] showed that the creation of a gradient in scaffold porosity and pore size could influence human mesenchymal stem cells differentiation by impacting cell density and nutrients availability. It was hypothesized that 3D scaffolds presenting a gradient structure could provide cues similar to the native environment and may guide stem cells to differentiate toward the lineage of the targeted tissue to be regenerated. Taken together the findings of Sobral, et al. [29] introduce pore size gradients as a structural factor that could be taken into consideration when combining scaffolds and stem cells for bone tissue engineering purposes. Interconnected porosity allows the supply of blood and nutrients for the viability of bone.

Furthermore, pore interconnectivity is defined as the following fraction:

$\frac{\text { Open Pore Volume }}{(\text { Open Pore Volume }+ \text { Closed Pore Volume })}=\frac{\text { Open Porosity }}{\text { Total Porosity }}$

where Open Porosity $=\frac{\text { open Pore Volume }}{\text { Bulk Volume }}$

Mechanical properties and cell/tissue ingrowth behavior depend on the pore size, total porosity and pore interconnectivity in different ways. In fact, porous biomaterials have much reduced Young's moduli compared to the dense counterparts, thus it is 
possible to match the Young's moduli of porous implants with those of bones. This match in young's modulus serves to minimize the problem of stress shielding. Stress-shielding is the phenomenon whereby a prosthesis having a biomaterial Young's modulus that is too high compared to that of its neighboring bone causes the degradation of this neighboring bone. Indeed, the Young's modulus of the biomaterial being greater, it provides a greater proportion of the stress support, thus leaving the bone under-stressed. The body will then respond to this under solicitation by sending osteoclasts to resorb the non-used bone.

\section{Porous Biomaterials as Dissipative Structure}

Biological structures have always been a source of inspiration for solving technical challenges in architecture, mechanical engineering, or materials science. It seems that the internal architecture of living tissue, including porosity gradients are self-organized phenomena that occur under conditions far from thermodynamic equilibrium. According to Prigogine, irreversible processes can be thought of as thermodynamic forces and thermodynamic flows; the latter being a consequence of the thermodynamic forces. For example, a concentration gradient is the thermodynamic force that causes the flow of matter. In general, the irreversible change in entropy $d_{i} S$ is associated with a flow $d X$ of a quantity, such as matter, that has occurred in a time $d t$. For the flow of matter, $d X=d N m o l e s$ of substance that flowed in time $\mathrm{dt}$.

Thus, the change in entropy can be written in the form (1):

$$
d_{i} s=F \cdot d x(1)
$$

where $\mathrm{F}$ is the thermodynamic force.

For the flow of matter, the thermodynamic force is expressed in terms of affinity.

Mainly, the irreversible increase in entropy $d_{i} S$ is the sum of all the increases due to irreversible flows $d x_{k}$ as in the general expression (2) or (3).

$$
d_{i} s=\sum_{k} F_{K} \cdot d X_{k} \geq 0(2) \text { or } \frac{d_{i} s}{d t}=\sum_{k} \frac{F_{k} d x_{k}}{d t} \geq 0(3)
$$

where $\mathrm{F}$ is the concentration gradient.

This is theSecond Law of Thermodynamics, where allirreversible processes can be described in terms of thermodynamic forces and thermodynamic flows. And the understanding of the formation of self-organized structures happening in open living systems is important to produce in vitro bioinspired gradient scaffolds. In fact, once the distance from equilibrium exceeds a threshold-level of stability, it evolves towards organized non-equilibrium states, so-called dissipative structures. In living systems like coral, the coupling of chemical or biological kinetics and diffusion give rise to ordered, compartmented spatial structures Rossi, et al. [30]. Entropy undergoes a sharp reduction because it is dissipated into the wider environment in these spatial ambits. The amount of entropy dispersed is greater than that produced by the system. In this way, the process is irreversible and spontaneous. Biotic systems pass from conditions of minimum entropy production to conditions of maximum entropy production, in which high dissipation creates and maintains system order. The basics of this concept are well illustrated by low-level self-organized systems, like the formation of Benard cells Prigogine, et al. [31]. The following (Figure 1) showing a coral from a family of reef building stony corals, exemplify the Benard-Rayleigh-like analogy. In 1922, the American statistician Alfred Lotka concluded that natural selection maximizes the flow energy which passes through an organic structure. Lokta, et al. [32] It works, he says explicitly, as a third law of thermodynamics. This statement is remarkable because, in 1922, the Maximum Entropy Production or MEP law was still unknown. Living beings being dissipative structures, MEP implies that they maximize the flow of energy that goes through them. Dissipative structures selforganize so as to maximize the energy flow that goes through them. They do this by producing free energy. They maximize their free energy production, in order to maximize the energy flux that goes through them. As a result, they maximize the rate at which energy is dissipated. It is said that the dissipative structures maximize the rate of production of entropy. Experts refer to this hypothetical law as the «law of maximum entropy production» or by the acronym MEP or MaxEP. The concepts of life, design and future (evolution) were placed firmly in physics by the Constructal Law, stated in 1996 Bejan, et al. [33] "For a finite-size flow system to persist in time (to live), its configuration must evolve freely in such a way that provides greater and greater access to the currents that flow through it." According to the Constructal Law, a living system is one that has 2 universal characteristics: it flows (i.e., it is a nonequilibrium system in thermodynamics), and it morphs freely toward configurations that allow all its currents to flow more easily over time. Life and evolution are a self-standing physics phenomenon, and they belong in physics Bejan, et al. [33]. Although it is currently impossible to determine the trigger, or establish where in the system the process arises, its beauty, stability and potentiality to evolve is lively testified within the biosphere. A magnificent organismic manifestation can be found in archaic invertebrates, within the Phylum cnidaria - commonly known as corals (see Figure 1). Although corallite development is rather complex, the modular morphology of Siderastrea share some essential features of Benard cells in that they tie together dissipative structures and the associated flow of energy to yield distinctive morphological phenotypes. 


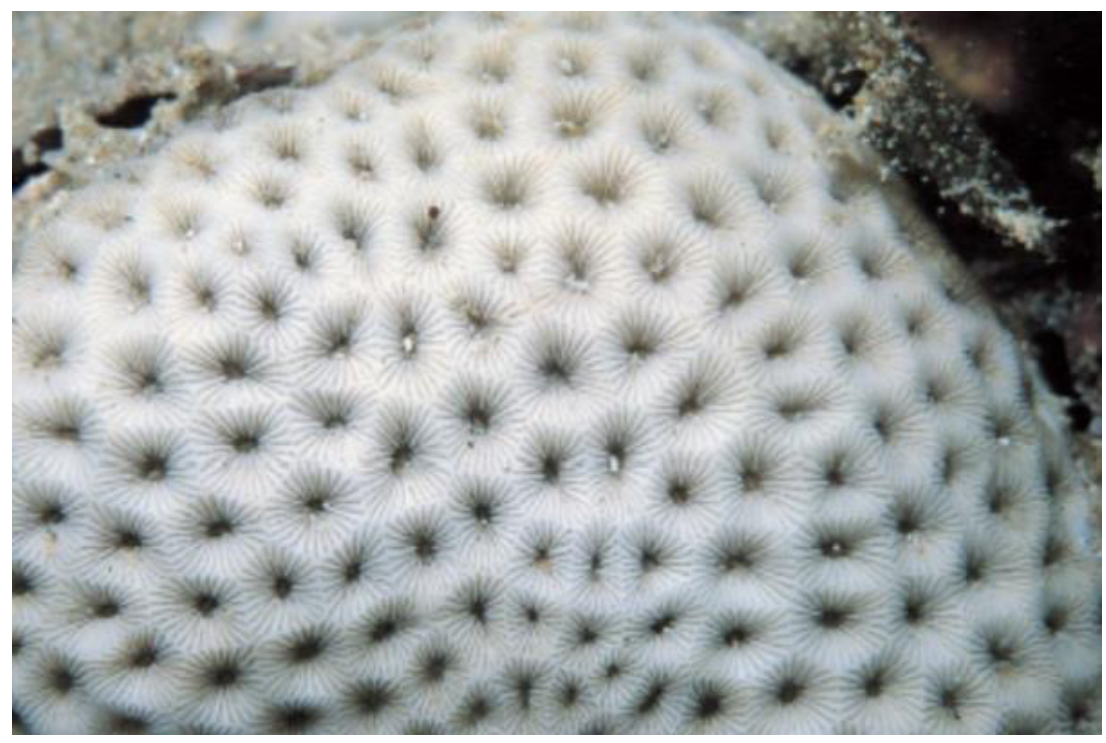

Figure 1: The ceroid arrangement of Siderastrea savignyana nicely illustrates the Benard-Rayleigh-like analogy. Each corallite is made of septa and dissepiments that by themselves assure regularity of this cyclic pattern Rossi et al. [100].

This similarity with Benard-Rayleigh-like cell type, along with re-organization giving rise to a honeycomb-like appearance is not accidental at all even though it is biochemically rather than thermically driven Rossi, et al. [30]. Dissipative structures are robust structures that are formed outside thermodynamic equilibrium and are encountered at various scales in inanimate and living systems, for example in fluid convection, chemical autocatalysis, and in the organization of cells, organisms and ecosystems. They are ordered structures that differ from equilibrium structures (e.g., crystals) in that their patterns are stabilized by continuous degradation of energy taken from their environment into exported entropy, a process known as 'energy dissipation'. All living systems are dissipative structures because they dissipate (i.e., degrade by their metabolic activities) the energy of environmental sources into metabolic wastes and heat that export into the environment. The analogies of the thermodynamic interpretations of pattern formation observed between the Benard-Rayleigh convection system, an extensively studied inanimate dissipative structure of globally organized convective fluid motion Manneville, et al. [34], and the developmental module of the growth plate, can clarify the thermodynamic role of the biological processes involved in the formation of the patterns of developmental modules.

Both systems use imported energy to organize their components into macroscopic spatial patterns and maintain their patterns by continuously exporting entropy into their surroundings: heat at the low temperature plate in the Benard-Rayleigh convection, and chondrocytes dying by apoptosis Shapiro, et al. [35] (or 'chondroptosis' Roach, et al. [36] cell self-disintegration which is more reminiscent of entropy production in physicochemical systems) in the growth plate. The thermodynamic significance of the biological processes taking place in the formation of the growth plate pattern may indicate a deeper relationship between developmental mechanisms and the physical mechanisms of pattern formation in inanimate dissipative structures. Interestingly, it has been argued that developmental mechanisms have originated in the early history of multicellular life through physical mechanisms that were in place long before the elaboration of complex genetic programs for pattern formation by evolution Newman [37]. These mechanisms, which were progenitors of the contemporary tissue shape transformations in embryonic processes, involved the action of physical forces, such as gravity, phase separation, adhesion, and interfacial tension, on multicellular clusters that exhibit viscoelastic behavior susceptible to such forces. The ancestral physical morphogenetic mechanisms were later stabilized by evolution, which installed complex genetic programs that fine-tuned and consolidated them Newman [37]. The above considerations justify the study of developmental modules as dissipative structures for determining new rules for the fabrication of authentic tissue structures, in direct relation with the physical laws. Ingber, et al. [38] suggested to use this dissipative structure approach to optimize the design of scaffold for tissue regeneration Ingber, et al. [38]. This will then permit the design of thermodynamically optimal scaffold geometries that could facilitate the energy dissipation and consequently the in vitro formation of multicellular patterns similar to authentic tissue structures. A scaffold design methodology, based on thermodynamically relevant indices that incorporate key design parameters, can circumvent the vast combinatorial combination of parameters that are presently tested with trial-and-error approaches, which create difficulties in deciphering their relative importance Ingber, et al. [38]. The term biomimicry was coined by biologist Janine Benyus in her 1997 book Biomimicry-Innovation 
Inspired by Nature, where she reintroduced the term to scientific literature and widely broadened its usage Benyus [39]. The Earth's biological materials and the processes through which they're generated represent the fruits of about 3.8 billion years of research and development.

Biomimetic materials such as coral exoskeletons possess unique architectural structures with a uniform and interconnected porous network that can be beneficial as a scaffold material for bone regeneration. We were among the first to postulate that the porosity gradient of biomaterials played a crucial role in the regeneration and growth of bone Hernandez et al. [40]. Recently, this hypothesis was confirmed in TCP scaffolds Zhim, et al. [27,41]. In another recent contribution, Vincent, et al. (2019), revisited the classification of 3 published mechanisms underlying Nature-inspired engineering, namely hierarchical transport network, force balancing and dynamic self-organization, by setting them in a broader framework supported by nonequilibrium thermodynamics, the Constructal Law and nonlinear control concepts. In fact, the literature shows that there is no definite pore size range that can be considered as a benchmark for scaffolds, e.g., for cartilage or for bone tissue engineering, some studies showed higher bioactivity with smaller pores while others showed better cartilage regeneration with larger pores. Macropores facilitate tissue ingrowth, nutrient supply, and waste removal while micropores facilitate cell attachment and better mechanical properties. One way to deal with the wide variations in pore sizes in the scaffolds is the introduction of gradient or hierarchical porosity, which is also observed in tissues such as skin, cartilage, and bone. Gradient porosity is also known to promote specific cell migration during tissue engineering, which is a requirement, e.g., for the treatment of articular cartilage defects in osteochondral tissue engineering Bretcanu et al. [42,43].

\section{Fabrication of Porous Biomaterials}

In the 1980s, in the USSR (Siberian Physical-Technical Institute), porous Nickel-Titanium (NiTi) alloys were obtained using the self-propagating high-temperature synthesis (SHS) process or combustion synthesis (CS) in an inert atmosphere, followed by successful clinical use of implant systems made of porous SHS NiTi Itin, et al. $[44,45]$. The SHS method to synthesize refractory ceramic compounds was initially proposed and comprehensively described by Merzhanov, et al. [46]. SHS, as a powder metallurgy method, turned out to be the most appropriate for the fabrication of the porous NiTi body having the specified characteristics Li, et al. $[47,48]$. Changing SHS variables such as starting powders, loose compacting degree, heating rate/schedule, ignition temperature etc., one may fabricate the different structure of porous body having a particular pore size and predetermined pore size distribution, which is known to be so crucial in cellular and tissue engineering Gunther, et al. [49]. Historically, it seems that porous NiTi was developed initially in Soviet Union during the cold war to trap hydrogen isotopes Rames, et al. [50]. Nuclear fusion constitutes a new source of energy that needs the use of significant amounts of deuterium and tritium. In fact, certain fusion reactors could generate large volumes of gas consisting of helium and hydrogen isotopes. These complex mixtures must be treated directly on site, so that tritium can be recycled.

Hydrogen isotopes have the particularity of showing significant differences in terms of mass: hydrogen or protium (the lightest isotope), deuterium and tritium. One of the most important separation technologies in modern industry is the physisorption separation method. Perfectly reversible, physisorption on porous solids makes it possible to reuse adsorbent materials, limiting the generation of waste. The development of safe and efficient adsorption methods is a prerequisite for the use of hydrogen with fuel cells for transport applications. Porous materials such as activated carbons or metal organic framework materials are used for hydrogen adsorption Thomas [51]. The porous NiTi material may also be employed in other applications, for example, in a flame torch, where the porous NiTi is fabricated as the torch head to provide a desired flame formation. A further application is as the working element of a surgical tool where the porous structure may act as a reservoir for a cooling liquid where the tool is employed in cryosurgery. In the case where the working element is a cutting edge or tip, the cooling liquid in the porous structure may provide local freezing at a site where a cut or incision is being made, such as in wart removal (Gunter, personal communication). A collaboration with the CEA Paris-Saclay1 (centre d'études atomiques) allowed us to develop a process for manufacturing of porous intermetallic alloys of the Ti-X or Ti-X-X type with open and controlled macroporous and microporous structures, both in terms of pore dimension and pore ratio Daumas, et al. [52]. These intermetallic alloys are designed to provide various industrial uses wherein either the presence of titanium is necessary such as prostheses, filtering elements, hydrogen or hydrogen isotope storage, or the titanium-X combination enables to obtain elements having all or part of the characteristics of shape memory alloys Daumas, et al. [52]. Another collaboration with Gunter's Tomsk group, allowed us to conduct studies in the early 2000's to qualify porous NiTi as a new biomaterial for biomedical applications Hernandez, et al. $[53,54]$. We hypothesized that the pore interconnectivity and superelasticity of NiTi give the implant pump-like and capillary properties which cause absorption of surrounding fluid. These, in turn, provide the conditions by which bone progenitor cells and blood vessels can grow into the implant pores Hernandez, et al. [53]. In other words, the capillary force controls the transport of fluid through the pore channels and on the other hand the material's wettability affects the velocity of fluid in its capillary spaces. This combination, capillary force, and wettability has been observed to 
allow bone penetration through the pores into internal structures of the implant Hernandez, et al. [53]. Thus, a porous NiTi implant is also more bioactive than bulk NiTi due to osteoblasts presenting good attachment and proliferation on the surface of textured and/or porous NiTi implants as well as the possibility of stiffness matching of the implant to the adjacent host bone Chu, et al. [54,55] performed in vivo experiments that compared un-grafted, porous NiTi and non porous, but otherwise standard, Ti-6Al-4V implants (i.e., "cages") in a mature sheep lumbar spine model for 3,6 , and 12 months. They did a quantitative analysis of osseointegration by using radiological fusion outcome. Their results showed an increasing time-dependent trend of osseointegration from 22 to $38 \%$ in the case of using porous NiTi implants while porous Titanium (i.e., Ti-6Al-4V) implants showed less increase in bone osseointegration (23-25\%) Assad et al. [54,56]. The capillarity may be produced in the material by inclusion therein of a large number of pores of fine size which interconnect to produce capillary passages. Capillarity is advantageous in that it promotes migration of a desired fluid material into the network of passageways, and retention of the fluid material in the network, without the need to apply external hydraulic forces.

Twenty years later, Aihara et al. [57] confirmed our previous results on capillarity by combining wicking tests and animal implantation. The vertical wicking test, which measures the rise of liquid on fabric with the immersion of one end of the fabric into liquid, is a preferred test method to determine liquid transport properties of the fabrics. A wicking test was performed on porous Nitinol, Physical Vapor Deposition (PVD) porous tantalum, and sintered porous titanium. The total amount of solution wicked by the 3 materials varied greatly. Porous Nitinol sintered porous titanium (Ti) and PVD porous tantale (Ta) wicked 91.2\%, 23.6\% and $0.9 \%$ of the overall percentage of the open volume at the duration of the test, respectively. Porous Nitinol exhibited exceptional wicking, achieving approximately $78 \%$ of the open volume wicked within 10 seconds, while sintered porous Ti and PVD porous Ta only exhibited $20 \%$, and $0.9 \%$ absorption, respectively. It is astonishing to observe that most of the wicking occurred within the first 10 seconds of the experiment. A video of the wicking demonstration can be found by going to following link (https://www.youtube. com/watch? $\mathrm{v}=\mathrm{tSTaYY} 1+2 \mathrm{kM}$ ). An ovine study in cortical sites of the tibia demonstrated rapid osseointegration into the porous structure as early as 2 weeks and complete bone growth across the implant at 6 weeks. A separate ovine study showed complete growth of bone at 4 months using a lumbar interbody fusion model, substantiating the use of porous Nitinol as an implant material for applications in the spine. Porous Nitinol exhibited exceptional wicking properties absorbing faster and more volume than the other porous metals tested. PVD porous Ta exhibited an almost hydrophobic behavior in comparison. The exact cause for this remarkable behavior is unclear, though likely due to combination of the pore characteristics and the chemical make-up of the porous Nitinol material. Regardless of the mechanism of wicking, it appears likely that it is this wicking behavior that results in the extraordinary bone ingrowth response of porous Nitinol. The material's random pore variations and the highly interconnective open pores may be beneficial for transferring nutrients and fluids which aids in early vascularization, cell response and osseointegration which are crucial for biomedical applications. Using the SHS process, Ayers, et al. [58] were able to control the porosity gradient. This approach is based on the novel use of combustion synthesis for producing TCP net-shaped materials and provides a means for forming such materials with better control of the porosity and the ratio of alpha and beta TCP in the final material. A combustion synthesis reaction is an exothermic chemical reaction process that utilizes the excess heat/energy generated during a reaction (without additional energy input) to ignite unreacted portions of the mixture, thereby producing the desired final product. An advantage of using combustion synthesis to form the final product is that combustion synthesis is an efficient and economical process of producing materials. A collaboration between our laboratory and Moore's NASA laboratory, porous biomaterials have been produced using SHS process Ayers et al [59]. We have approached this challenge by utilizing combustion synthesis, to create novel materials such as $\mathrm{NiTi}+\mathrm{TiC}$ as well as porous forms of materials that are commonly accepted for biomedical applications such as TCP and HA. In the SHS product, Physico-chemical properties are controlled by, but not limited to, reactant stoichiometry; green density; particle size of the reactant mix; use or presence of a gasifying agent; heating rate of the reactants and gravity.

By balancing these parameters, the energy of their action is controlled to create the desired product stoichiometry, porosity, and mechanical properties. SHS provides a means to rapidly manufacture materials, saving time and production costs as well as enabling the synthesis of custom devices with individual molds. Mold materials can range from graphite to paper or paper machete. Combustion synthesis offers a method for the rapid manufacture of affordable, individual biomedical devices that will reduce patient recovery time. Therefore, we developed a new generation of bioceramic personalized implants Zhim et al. [27]. This technique combines the processes of solid freeform fabrication (SFF) and combustion synthesis (CS) to create personalized bioceramic implants with TCP and HA. These porous bioceramics will be used to fill the tibial bone gap created by the opening wedge high tibial osteotomy (OWHTO). A freeform fabrication with three-dimensional printing technique was used to fabricate a metallic mold with the same shape required to fill the gap in the 
opening wedge osteotomy. The mold was subsequently used in a CS process to fabricate the personalized ceramic implants with TCP and HA compositions. The mold geometry was designed on commercial 3D CAD software. The final personalized bioceramic implant was produced using a CS process. This technique was chosen because it exploits the exothermic reaction between $\mathrm{P}_{2} \mathrm{O}_{5}$ and $\mathrm{CaO}$. Also, chemical composition and distribution of pores in the implant could be controlled. To determine the chemical composition, the microstructure, and the mechanical properties of the implant, cylindrical shapes were also fabricated using different fabrication parameters. Chemical composition was performed by X-ray diffraction. Pore size and pore interconnectivity was measured and analyzed using an electronic microscope system. Mechanical properties were determined by a mechanical testing system. The porous TCP and HA obtained have an open porous structure with an average $400 \mu \mathrm{m}$ channel size. The mechanical behavior shows great stiffness and higher load to failure for both ceramics. Finally, this personalized ceramic implant facilitated the regeneration of new bone in the gap created by OWHTO and provides additional strength to allow accelerated rehabilitation Zhim, et al. [27]. Recently, a novel biodegradable scaffold based on mimetic a natural bone tissue morphology with a porosity gradient structure was prepared by Wang, et al. [28]. The result of surface morphology indicated that a graded porous structure was formed in the fabricated scaffold, where the dense layer ( $0 \%$ porosity) was connected with the most porous layer $(60 \%)$ by a middling porous layer (30\%). To evaluate the degradability, graded porous scaffolds compared with homogeneous scaffolds were placed into a Tris- $\mathrm{HCl}$ buffer solution $\left(\mathrm{p}^{\mathrm{H}}-7.4\right)$ for 28 days. It was found that both scaffolds presented the same degradation trend, and the graded porous structure did not change the original degradability of the scaffold. Moreover, the compressive strength of the graded porous scaffold was better than that of conventional homogeneous scaffold with the increase of degradation time, and the graded porous structure can enhance the mechanical property of the scaffold. These findings suggest that this biodegradable and porosity-graded scaffold may be a new promising scaffold for loaded bone implant.

\section{Coral as an Ideal Biomaterial}

A Bone Graft Substitute: Even though experiments on natural coral as bone substitute started back in the 1970s Hulbert et al. $[60,61]$ coral is still not a well-known material. One reason is that most reports of the earlier experiments on coral were published in French. Eugene White realized in the late 1980s that coral's porous structure which channels nutrients and aids communication throughout the coral's colony resembles the spongy structure of bones White et al. [62]. Coral, he thought, would make great bone grafts. The pores of the coral skeletons were uniformly sized, evenly distributed, and completely interconnected, which would allow bone and blood cells to flow through the implant and new blood vessels and bone tissue to grow into the graft. White et al. [62] outlined some of these advantages in a 1972 paper in Science and suggested that Porites coral, often called finger coral, might make a particularly good source of implant material. Chiroff and coworkers placed calcium carbonate (CC) in cancellous defects in dogs for 8 weeks and found that the material was biocompatible and that new bone could fill the pores. Some implants were left for 1 year and were observed to be almost completely resorbed Chiroff et al. [62]. The favourable results were confirmed when other animals, e.g., monkeys Souyris, et al. [63-65] and sheep and pigs were used.

The first clinical reports were published in France by the "Institut de Recherches Orthopédiques, Université René-Descartes Paris V" in 1980 Patel, et al. [66]. Since then, CC has been used clinically in maxillofacial surgery to correct periodontal defects $[67,68]$ and to fill and reconstruct bony defects in cranial surgery Roux, et al. $[69,70]$. The craniofacial bones can be augmented by the granular form of CC Marchac, et al. [71]. In orthopaedic surgery CC has been used as a filler in tibial osteotomies Kenesi, et al. [72], in bone tumour surgery Rouvillain et al. [73] and in lower limb metaphyseal fractures to support articular surfaces de Peretti, et al. [74]. The possibly most appropriate indication at the moment is spinal fusion, where CC can be used to diminish the amount of bone grafts in conjunction with autogenous bone Pouliquen, et al. [75]. Very little exact information exists also on the resorption time of CC. It seems to depend on the animal species used. When the implant was placed in the cortex of the femur in pigs, $64 \%$ of the CC blocks were resorbed after 1 month, whereas in sheep the figure was 93\% Guillemin, et al. [65]. The granular form has been observed to resorb completely at 24 weeks in a connective tissue site in pigs but, in humans, the same material placed in subcutis can still be found after several years Marchac, et al. [71]. Roux and coworkers reported almost complete resorption after 1 year in $50 \%$ of cases when coral was used to fill craniotomy burrholes in humans Roux, et al. [69]. Larger blocks used in humans have still been X-Ray positive after 4 years de Peretti, et al. [74]. Coral resorption is most active in the bone implant contact areas and proceeds centripetally Braye, et al. [76]. Carbonic anhydrase, an enzyme abundant in osteoclasts, plays a key role in the resorption process. Locally it lowers the $\mathrm{pH}$ at the osteoclast implant interface, dissolving the CC matrix Chétail, et al. [21,22,61,77]. Resorption can be halted by the administration of the diuretic acetazolamide, a known inhibitor of carbonic anhydrase Guillemin, et al. [61]. Moreover, according to Fricain and coworkers, data suggest that both fibroblasts and macrophages dissolve the coral, and that one of the mechanisms is the intracellular degradation in phagolysosomes [78]. A prerequisite for the process is direct contact between these cells and the coral matrix [79]. The structure of the commonly used coral Porites, is similar to that of cancellous bone, and its initial mechanical properties resemble those of bone [80]. 
The exoskeleton of these high content calcium carbonate scaffolds has since been shown to be biocompatible, osteoconductive, and biodegradable at variable rates depending on the exoskeleton porosity, the implantation site, and the species Oladeji, et al. [81]. Although not osteoinductive or osteogenic, coral grafts act as an adequate carrier for growth factors and allow cell attachment, growth spreading and differentiation. When applied appropriately and when selected to match the resorption rate with the bone formation rate of the implantation site, natural coral exoskeletons have been found to be impressive bone graft substitutes Demers, et al. [10,12]. The harvested coral is purified physically and chemically, and the final implant material contains no proteins and less than $0.1 \%$ amino acids. The manufacturer of the commercially available coral implant $\left(\right.$ Biocoral $\left.^{\circledR}\right)$ guarantees the following chemical composition of the product: calcium carbonate: $>97 \%$; trace elements: 0.5-1\%; magnesium: 0.05-0.2\%; sodium: $<1 \%$; potassium: $<0.03 \%$; phosphorus: $<0.05 \%$; water: $<0.5 \%$.

Injectable Coral Biomaterials: An injectable biomaterial could be defined as a biomaterial that is deliverable to the place of interest (in situ) through a syringe, hence enabling a minimally invasive procedure. Injectable bone cements have a long history of clinical use. Ceramic cements were first introduced in 1892 by Dressmann [81], who used calcium sulphate as filler to repair bone defects, whereas polymeric cements were later introduced in 1941 by Kleinschmitt (1941) who used acrylic cements for closing cranial defects in humans, followed by Sir John Charnley (1964), who used them to anchor hip joint prostheses. Injectable biomaterial systems are also described in terms of other properties that are directly related to their applicability and are of particular interest to the physicians. Enough radiopacity is a usual requirement of injectable biomaterials, since it allows monitoring of the delivery, as well as the final positioning of the implant.

Dr Cirotteau came up with the idea of mixing the coral beads with the patient's bone marrow before injecting the mixture Nassiri, et al. [82]). Back in 1869, Goujon observed heterotopic (extraskeletal) bone formation after red bone marrow transplantation. Bone marrow contains osteogenic precursor cells, which are capable of differentiating into osteoblasts. When marrow is placed in a heterotopic site (subcutis, muscle), bone may derive from these cells, from endosteal osteoblasts or from the host cells at the site of grafting, induced to differentiate by bone marrow Burwell [83]. In 1971, it was found that autogenous marrow formed bone in association with various materials and that calcified matrix increased the ostegenic capacity of the marrow Newman, et al. [84,85]. In 1980, reported enhanced bone formation in composite grafts of bone matrix and bone marrow. A year earlier, McDavid and coworkers had placed TCP pellets with autogenous bone marrow under the skin of rats. At 4 weeks, bone was evident only in marrow-coated implants McDavid, et al. [86] Porous aluminate, calcium aluminate, HA and TCP inserted together with marrow into the intermuscular space of rabbits were observed to allow bone formation Nade, et al. [87]. The use of injectable biomaterials is currently growing as the demands for minimally invasive procedures, and more easily applicable implants become higher.

However, their clinical availability is still limited due to difficulties associated to their design. Injectable biomaterials are usually referred to as 'bone cements' if they are intended to interact mostly with bony tissue, although soft tissue applications are also becoming more important, in which case the biomaterials are generally referred to as just 'cements', or 'scaffolds' if also intended for tissue regeneration. Injectable and fully degradable radiopaque ceramics may be of interest not only for vertebroplasty Belkoff, et al. [88] with nonacrylic materials, but also for dentistry Hill, et al. [89] and other novel orthopedic applications that demand radiocontrast such as tibioplasty Pizanis, et al. [90], proximal humerus augmentation Gradl, et al. [91], and femoral head treatments Ng, et al. [92]. Strontium halides, except strontium fluoride, are watersoluble and previous investigations have indicated their potential as radiopacifiers Wiegand, et al. $[93,94]$. To conclude, it is important to recognize that developing materials that can be delivered through a syringe is overall a major challenge, since, assembly of the final implant is intended to proceed in vivo, where the conditions are relatively harsh, difficult to control, and sometimes unpredictable.

\section{Case Study- Personal Series}

\section{Abstract}

This is the story of a patient that has been hospitalized following a car accident for a complex fracture of the lower third of the femur. However, the bones non-union is confirmed. It was then necessary to perform another surgery, removing the initial material in addition to carrying out an anatomical reduction. A screwed plate- blade Poitout, et al. $[95,96]$ and a biomaterial graft Cirotteau, $[97,98]$ are performed to stimulate new osteosynthesis. Consolidation took 4 months; the femoral shaft is anatomically reconstructed in 1 year and there were no sequelae. The followup was made on a period over 2 years. This case study highlights, among other things, the essential role of vascularization. And the results are supported by more than 300 other femoral fractures treated according to the same surgical procedure.

\section{Clinical history}

On August $12^{\text {th }}, 1999$, Miss Hélène G ..., aged 20, had an emergency surgery when she came at the hospital. The lower third of her femur was fractured. It was a complex fracture including bone non-union. The femur was osteo-synthesized using a long plate. The patient refuses a re-operation proposed by the second 
surgeon despite the practitioner's insistence and against the advice of the family. She persisted in her refusal for 7 months, before finally accepting the procedure.

\section{Method and Technique}

The operation took place on March $7^{\text {th }}, 2000$. Using the technique described by Robert Judet, et al. [99] the surgeon dissects the nonunion area after removing the initial material. Then he wraps it in a natural coral biomaterial Guillemin, et al. [20,100]. Anatomical reduction of fracture foci is temporarily maintained by forceps and securely fixed by a plate blade Poitout et al. [95,96]. A short antibiotic therapy (5 days) was prescribed. The aftermath was simple. From the $12^{\text {th }}$ day, the patient was authorized to use partial support with 2 crutches, and she underwent a few rehabilitation sessions. After 3 months, the patient was able to let go of one of the crutches and the abandonment of the second followed after the $4^{\text {th }}$ month. At the $3^{\text {rd }}$ month clinical examination, the mobility of the knee was normal, there was no more lameness, and the femur was painless. After 8 months, the patient was able to regain normal muscle mass. After 1-year, unrestricted sports activity was allowed. The follow-up was up to 2 years.

\section{Equipment}

Plate-Blade: The material of the plated blade is stainless steel Poitout et al. $[95,96]$. The $6.5 \mathrm{~cm}$ long blade is bent at $95^{\circ}$ and is drilled with 9 holes for $5 \mathrm{~mm}$ diameter screws. The 3 upper screws take 6 cortices above the most proximal fracture line. Biomaterial: Natural coral Guillemin et al. [100] is Porites, with a porosity of $50 \%$ in which fluid can flow and interconnecting pores with an average pore size between 150 to $500 \mathrm{~mm}$. The circulation of bone marrow cells (as well as blood fluids, anions, cations ...) is favored by the volume, the thickness of the walls of the pores and the structural regularity. The biomaterial, which is $98 \%$ Calcium Carbonate, is used in the form of spheres 1.5 to $2 \mathrm{~mm}$ in diameter. The architecture of natural coral is favorable to bone growth. In addition, natural coral has remarkable mechanical properties such as resistance to compressive stresses, even when the pore volume approaches $50 \%$, which is identical to that of cancellous bone. However, the mechanical strengths in bending and in torsion are low.

a) Biocompatible: The human body completely tolerates this biomaterial without risk of contamination. The biomaterial is biocompatible with the structural requirements of bone growth. b) Bioresorbable: Guillemin, et al. [61,65]. The biomaterial is completely reabsorbed between 2 and 6 months. The integration of the calcium carbonate backbone is attributed to the enzyme carbonic anhydrase it contains and which releases $\mathrm{H}^{+}$ions through osteoclasts.

c) Bioactive: Autologous blood and bone marrow cells penetrate and diffuse rapidly in natural coral as soon as it is placed in the bone site thanks to its mineral and architectural characteristics (Aragonite crystal and porosity). From the 9th day, calcification is initiated.

d) Osteoconductive: The porosity provides space for rapid invasion of the bone marrow and allows integration of newly formed bone. The bone mineralization process is reset by the coral biomaterial. The latter is rapidly vascularized and gradually absorbed by osteoclasts Guillemin, et al. [100] then replaced by osteoblasts Triffitt [101] to direct new bone formation identical to the recipient's bone. The first step in the bone restoration process is characterized by the development of neovascularization through initial cell penetration. This biomaterial, Porites, is very similar to cancellous bone.

e) Bone Marrow: 3 to $6 \mathrm{cc}$ of bone marrow are taken from the iliac crest of the patient using a Mallarmé trocar and are absorbed by the biomaterial in the center of the coral spheres. They are mixed extemporaneously with the biomaterial and heparin. The composite formed resembles frog spawning. It is a compact amalgam which is easy to inject.

\section{Evolution of vascularization of a long bone}

It is well known that vascular supply changes over time Kadiyala, et al. [102]. In toddlers, the vascular supply to the cortex emanates exclusively from the bone marrow (Figure 2). The richly vascularized periosteum is perfectly integrated with the cortex and does not penetrate. At a later age, the quality of vascular supply to bone tends to decline. In this angiographic section of a crosssection of a 42-year-old femur see Figure 3, the robust medullary arteries supply the entire cortex apart from the right part of the posterior cortex where traces of periosteal arteries are detected. Furthermore, the vascularization of the shaft of a mammalian long bone is longitudinal crossing the major axis of the bone in the middle of the bone marrow. Here in Figure 4 there are 2 nutrient systems, one proximal, the other distal. 


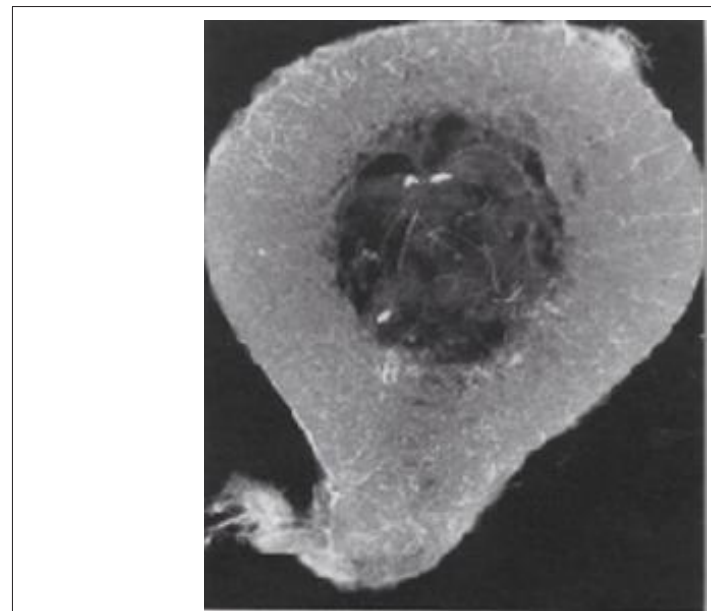

Figure 2: Angiograph of a transverse section of a femur (2-years-old) perfused in vivo. (Enlargement x3) Brookes, et al. [121].

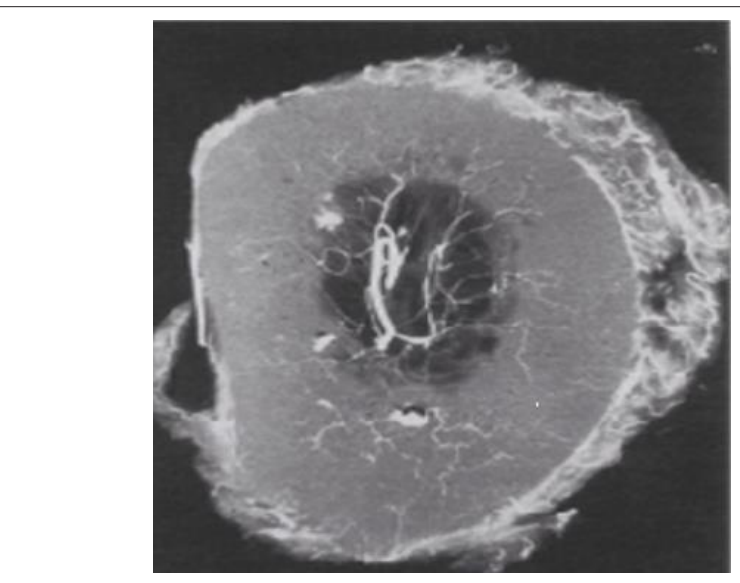

Figure 3: Angiograph of a transverse section of a femur (42-years-old). (Enlargement x3) Brookes, et al. [121].
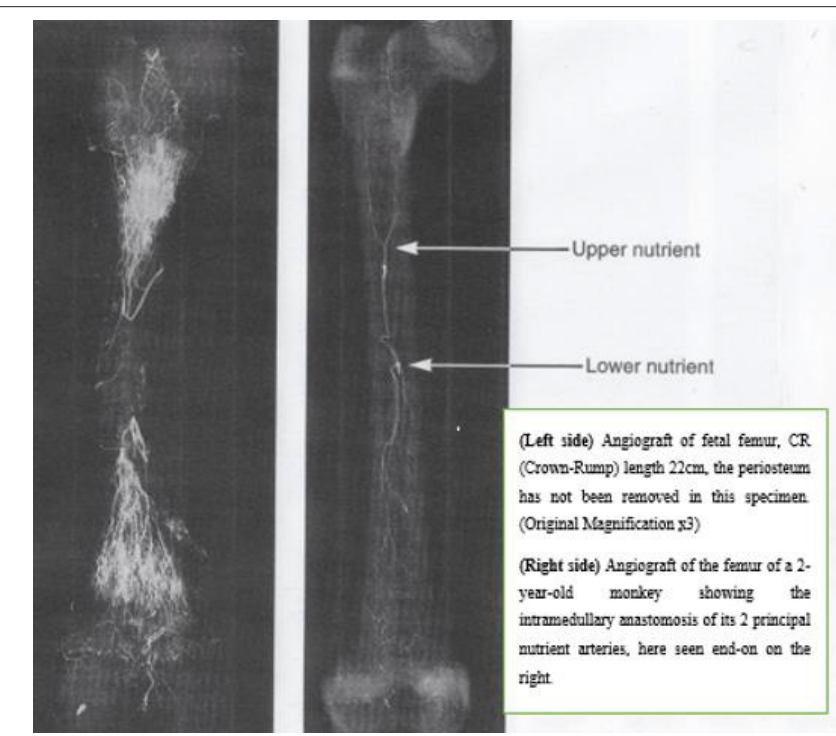

Figure 4: The main artery has a longitudinal direction. Brookes, et al. [121].

\section{Resorption of Natural Coral Grafts}

Rejection phenomena have been observed - both clinically and histologically, in cases where the coral used was of large size (For example with osteotomy wedges greater than $5^{\circ}$ ). It has been proven that the foreign body reaction was due to insufficient purification at the core of the biomaterial. The development of a technique using supercritical fluids by Prof. Yann Le Petitcorps \& coworkers, made it possible to remove the remaining proteins from the core. The biomaterial, thus purified, has been used without any rejection, nor any reaction to foreign body.

The coral purification was obtained down to the aragonite crystal using super-critical fluids according to the technique developed by Professor Le Petitcorps see Figures 5\&6.
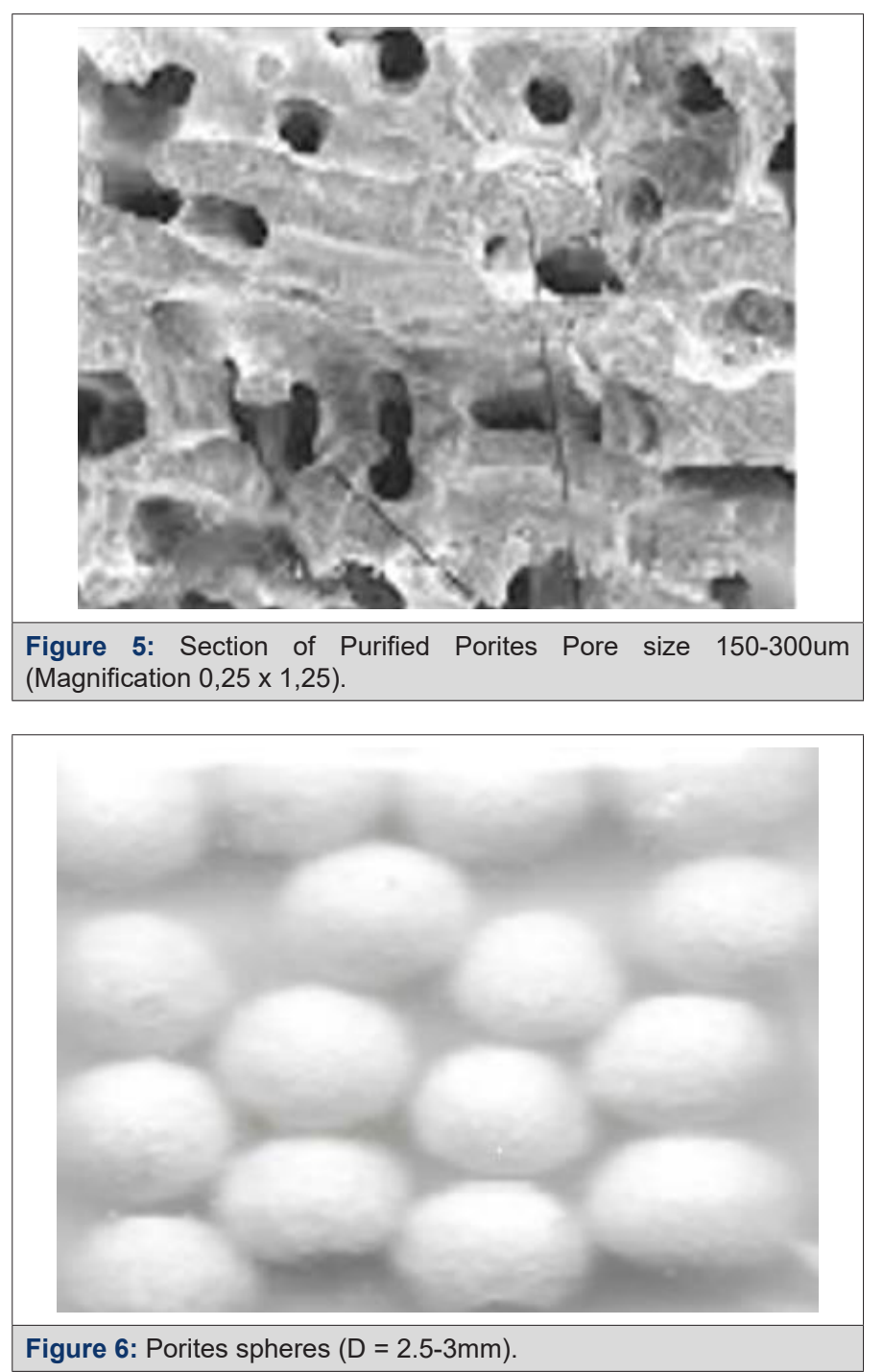

\section{Role of Vascularization}

In necrotic bone or in bone in contact with inert metallic material (such as a plate, screw, nail), there is no possibility of 
developing adequate vascularity. The (Figure 7) shows as an example that there is no modification of the biomaterial of the coral Porites spheres in contact with the inert metallic biomaterial. In fact, the biomaterial remains in the mineral state, surrounded by an avascular fibrous sleeve. This supports the argument that vascularization has a fundamental role. On the contrary, adjoining the well-vascularized cancellous bone, the biomaterial is integrated and assimilated by a double mechanism: demineralization process with the osteoclast's activities, then remineralization process with the osteoblast's actions, and a newly formed bone appear as shown in Figure 8.

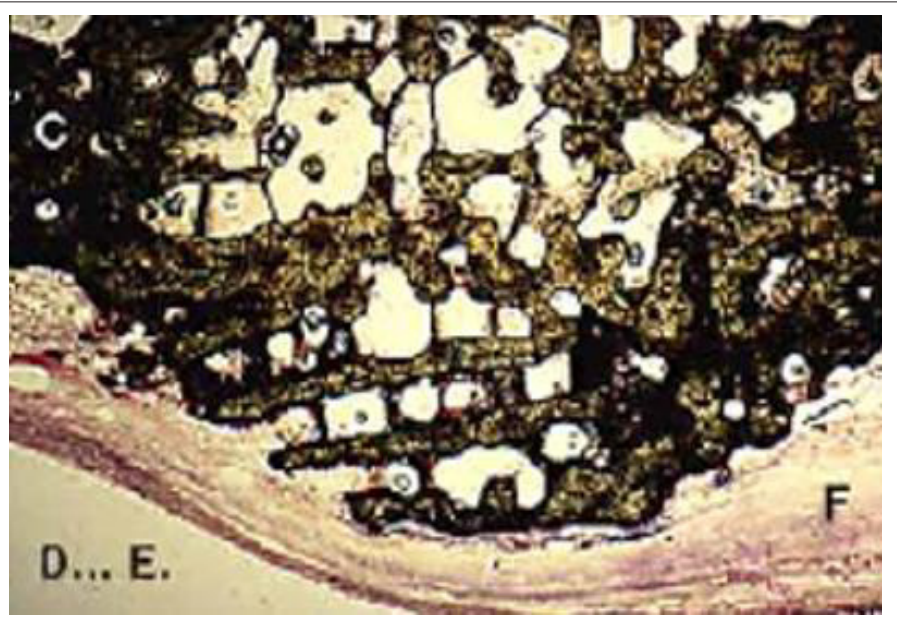

Figure 7: The natural coral Porites spheres in contact with inert metallic material have remained intact. They were surrounded by fibrous tissue without vessels. (Magnification $0,35 \times 1,35$ ).

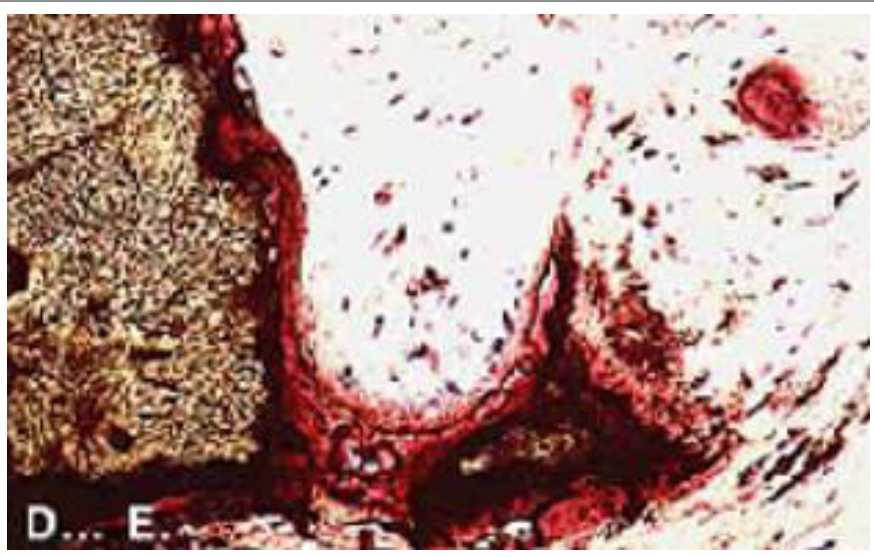

Figure 8: The coral spheres in contact with the bone and the vessels that run through it have been colonized by bone cells which have undertaken the resorption of the biomaterial. (Biomatech laboratory) (Magnification $0,35 \times 1,35$ ).

\section{Methodology of the Mechanical Evolution of Coral Graft}

On the frontal and lateral radiographs (taken at 1 meter distance, by the same operator and with the same device), it is visually possible to distinguish the spheres of coral infused with bone marrow which are clearly individualized. On the anterior and posterior surfaces (in lateral radiography) and on the external and internal surfaces (in frontal radiography), the spheres were counted and then recorded on a sheet of millimeter paper as shown in Figure 9. They were counted at different stages of consolidation. In fact, there are 5 phases of reconstruction. In phases III and
IV, an alignment of the external spheres along the major axis of the diaphysis was observable, suggesting the beginning of the organization of the Haversian system. This example, shown in Figure 9, is that of a young patient, 19-years-old, suffering from a non-union of the femur treated by 2 external fixators (front and side), thus allowing the counting of the balls on the 4 faces. It can be seen that the resorption is identical at the level of the 4 faces. By plotting the number of remaining spheres as a function of time on a graph presented in Figure 10, one obtains a logarithmic plot in geometric degression, suggesting an identical and coherent physiological process of resorption. 


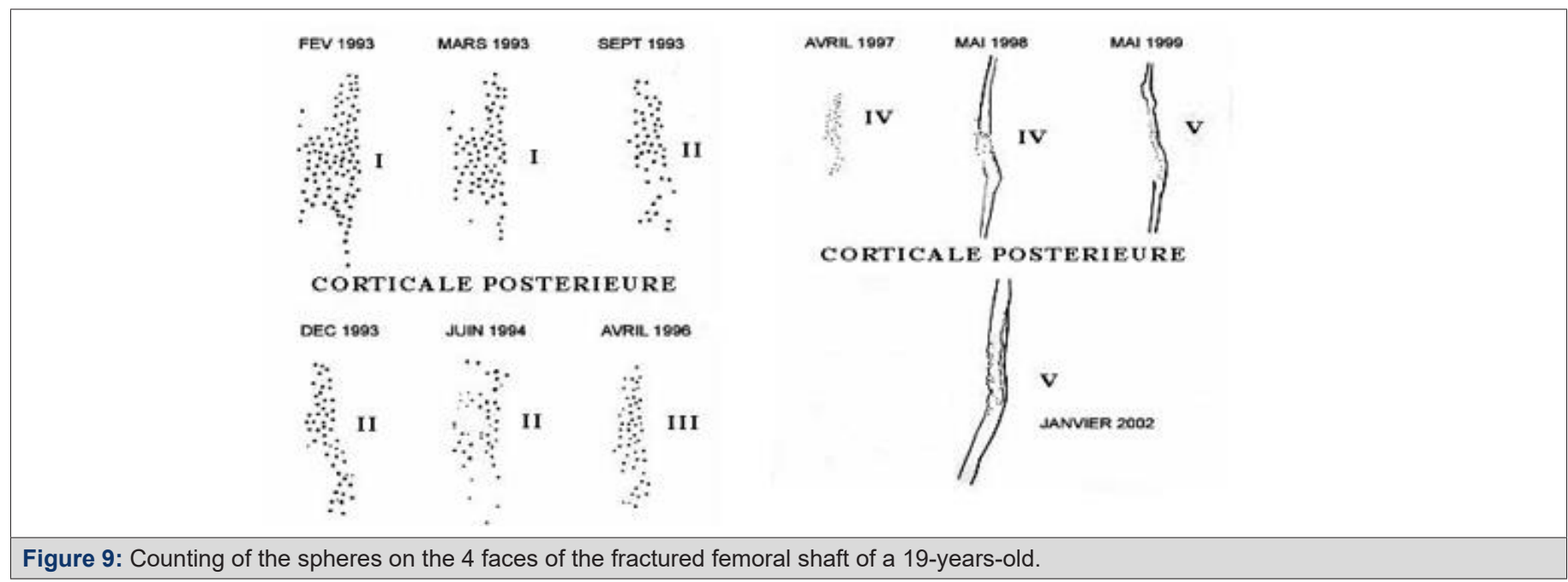

Figure 9: Counting of the spheres on the 4 faces of the fractured femoral shaft of a 19-years-old.

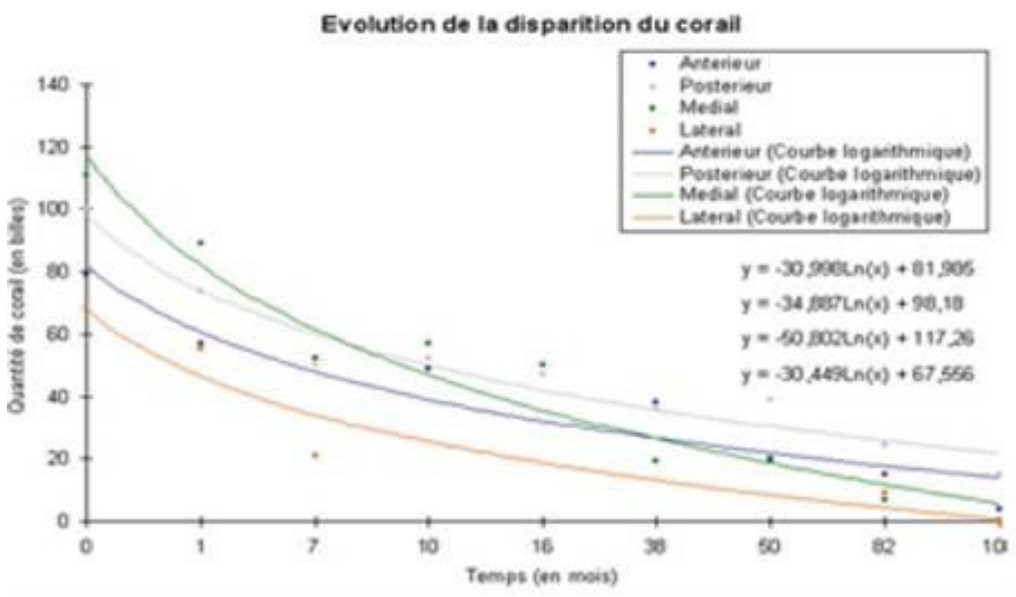

Figure 10: The disappearance of the coral spheres is identical at the level of the 4 faces of the diaphysis.

\section{Radiographic Evolution of the Femur of the Young Patient}

Here in this section, we go over the evolution (from 0 to 20 months) of the reconstructed bone of the 19-years-old patient. The radiograph story presented in Figure 11 depicts the new internal fixation and bone consolidation after 4 months. The reader can find in the following table1 the different stages of this remarkable reconstruction.

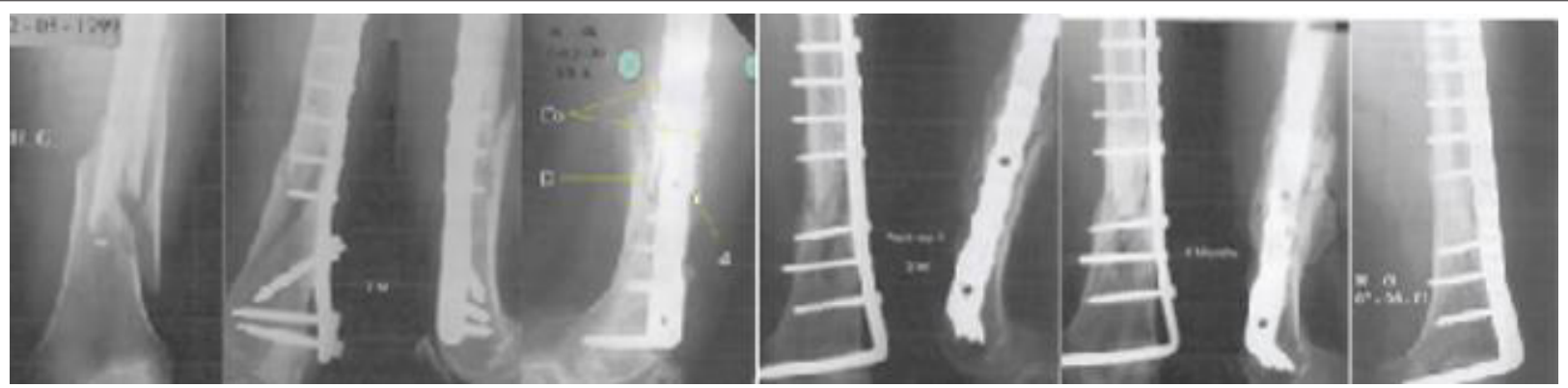

Figure 11: Non-union of a femoral shaft (at 7 months) taken over by a new osteosynthesis and a coral graft. Bone consolidation is seen after 4 months.

\section{Evolution of the Bone Mineral Density over Time}

There is a steady decrease in bone mineral density (BMD) over time. This decline begins on average in young adults around 23 years of age or as soon as the subject has reached bone maturity.
Interestingly, this natural evolution also takes place in patients whose fracture has been restored by combining osteosynthesis and biomaterial. Here in Table 2, the reader can appreciate the natural decrease of BMD in $\mathrm{gr} / \mathrm{cm}^{2}$ of 2 older patients of 80 and 94 years old. 
Table 2: Natural decrease in BMD over time.

\begin{tabular}{|c|c|c|c|c|c|c|c|c|}
\hline Name & Age & Exam Date & B.M.D. gr $/ \mathbf{c m}^{2}$ & $\mathbf{+ 3}$ months & $\mathbf{+ 6}$ months & $\mathbf{+ 1}$ year & +2 years & $+\mathbf{5}$ years \\
\hline M.O & 80 & $24 / 07 / 1992$ & 0.853 & 0.853 & 0.852 & 0.742 & 0.667 & 0.536 \\
\hline G.A. & 94 & $27 / 07 / 1992$ & 0.806 & 0.773 & 0.691 & 0.668 & 0.541 & \\
\hline
\end{tabular}

\section{Discussion}

On one hand, a fractured bone can consolidate if it is placed in a well-vascularized area. The fracture site must be stabilized by osteosynthesis, while leaving a minimal gap between the fragments; very little mobility not being an obstacle to consolidation. On the other hand, when the inter-fragmentary gap is important, when the focus is mechanically stable (very or too much) and when the vascularization is precarious, pseudarthrosis is inevitable. It is thus necessary to anatomically reduce all the foci of fracture and to keep them firmly stable to avoid this kind of serious complication. This stabilization is also crucial to allow resorption of the graft. It is also essential not to destroy the central medullary vascularization while respecting the bone physiology. Given the longitudinal arrangement of the medullary arterial system, it is imperative to re-establish this path over the entire length of the shaft interrupted by fibrosis located at the proximal and distal ends of the pseudarthrosis.

This fixation restores blood circulation by supplying blood and the elements required for bone metabolism. Besides, bone decortication using the $\mathrm{R}$ Judet technique is not an essential requirement for consolidation. It is a technique that was widely practiced before the appearance of biomaterials. In this particular case, the surgeon combined the 2 techniques convinced of the effectiveness of the method. Masquelet, etal. [103] Is it of importance to note that this choice has also been adopted by many surgical teams before Yukna et al. [69,104, 105,75,97]. Morever, Professor Yahia published a comprehensive review on coral grafting Demers, et al. [10]. It is noteworthy that there was no failure in the 25 cases of pseudo-arthritis (femur, tibia and clavicular bone). In this series of 25 cases of limb fractures or repair of loosened prostheses, mechanical stabilization allowed the transformation of the coral into autologous bone. (Unpublished data) The osteosynthesis material stabilized is there to allow the incorporation of the graft to the defect it fills.

\section{Conclusion}

This approach has been used in the treatment of multiple pseudarthroses of different aetiologies: in the case of delayed intervention, in the event of a technical error in most cases, in the context of chronic osteitis, or when unsuitable biomaterial was used etc. The fractures treated affected all the long bones of the human body, both in the upper limb and in the lower part. Natural coral (Porites), once purified, is no more than one. purely mineral skeleton. In order to become a living graft, it is necessary, and it is enough to add in living cells. For it to become an autologous live transplant, it is - and just - necessary to incorporate the cells of the recipient's bone marrow. Moreover, when the surgeon places a bone graft, he always stabilizes the fracture site using a rigid material to avoid micro-movements which would damage the constitution of the vascularization necessary for the taking of this graft. This stabilization is essential whatever the graft used. The multicenter, prospective, randomized, double-blind study confirms this view. The best results were obtained in the group using mechanical stabilization and a coral graft enriched with bone marrow. The next group using coral and a mobile stabilization came second because the mobility linked to the mobile screw-plate was done in compression of the coral balls, until the mechanical stabilization of the focus was obtained. Ultimately, a process that biomimics the metabolism of healthy bone - or considered normal cannot fail. It should be noted that no such therapy has yet been proposed for congenital malformations.

\section{Ecological and Ethical aspects}

This review paper revealed that coral has medical applications, particularly in the orthopedic and dentistry fields. It is based on the work of Dr. Cirotteau, the main inventor of the applications of natural coral in the preventive and in the curative treatments of osteoporotic fractures and who published a recent book to explain to the general public the nature of 3 species of corals Cirotteau [106]. This marine animal described by Aristotle, then by Al-Biruni, was rediscovered by a French surgeon André Peyssonnel in the $17^{\text {th }}$ century. Then, after much controversy, Buffon wrote: «Thus marine plants, which were first classified as minerals, then passed into the class of plants and finally remained forever in that of animals.»

\section{Nanoparticle Pollution}

In recent years, $\mathrm{TiO}_{2}$ and $\mathrm{ZnO}$ NPs in sun care products have received criticism for their possible adverse effects on humans and in the aquatic environment regarding the reactive oxygen species (ROS) they produce when exposed to sunlight Skocaj et al. [107]. Additionally, ZnO NPs are subjected to solubilization into harmful $\mathrm{Zn}^{2+}$ ions in seawater due to a higher $\mathrm{pH}$ environment Wong, et al. [108]. Consequently, non-nano $\mathrm{TiO}_{2}$ and non-nano $\mathrm{ZnO}$ (with nanoparticles measuring $>100 \mathrm{~nm}$ ) are becoming increasingly popular for sunscreen formulations produced by smaller, ecoconscious sunscreen companies Maipas [109]. Interestingly, of the countries that permit the use of mineral UV filters, their percentage limit for the amount of a UV filter contained within a sunscreen 
formulation is higher compared to most chemical UV filters (20$25 \%$ or no limit for mineral UV filters versus a $10 \%$ average limit for chemical UV filters).

However, commercial sunscreen formulas often contain a unique mixture of both mineral and chemical UV filters to produce a broader spectrum of protection Sánchez-Quiles [110]. Many sunscreen manufacturers claim that their sunscreens are "reef safe", but is that true? The studies presented in this capstone clearly demonstrate that even "ecofriendly" sunscreens can have negative effects on marine organisms at very low concentrations. Some claimed "reef-safe" brands contain UV filters that have reproductive inhibition in sediment dwellers Fabrega, et al. [111] when exposed to non-nano UV filter particles. Authors from these studies indicate that these organisms may readily uptake higher concentrations of larger non-nanoparticles due to their higher bioavailability. Still, non-nano UV filters are generally lower in toxicity than other types of UV filters and seem least toxic to Scleractinian corals compared to others.

Unfortunately, there are no current regulations that enforce the integrity of "non-nano" and "reef-safe" advertisement claims, but consumer awareness has recently demanded that manufacturers should be more accurate Sobek, et al. [112]. UV filters that seem promising to the health of marine organisms are non-nano $\mathrm{TiO}_{2}$ and non-nano $\mathrm{ZnO}$, based on their larger particle size and lower solubility rates in seawater Fabrega, et al. [111-114]. Contradicting studies, however, found that non-nano UV filters were more toxic to some marine organisms compared to smaller nanoparticles Wong, et al. $[108,115]$. Specifically, these studies observed DNA damage in hemocytes in filter-feeders D'Agata et al. [115], oxidative stress in crustaceans and fish Wong, et al. [108] and been shown to be toxic to marine life, both mineral and chemical UV filters.

\section{Coral protection}

A coral future in medicine can be assured by proper advances in: (i) coral farming; (ii) coral cultivation in captivity; and (iii) biomimetic generation of coral skeletons. Coral Farming. In a future with biomedical corals, farming aquaculture will be required, either in situ (mariculture), where ideal growing conditions exist, or ex situ, 'off-site conservation' (laboratory aquaria), in which the light intensity, nutrition, flow rates, and so on, are tuned to influence skeletal composition, morphology and topography Leal et al. [116]. Further advances will result from manipulating coral systems biology and symbiont systems. A few teams of coral aquaculturists, including commercialized operations, have built operations to grow certain corals for biomedical purposes. The production, and unnatural overgrowth, of coral biomass in aquaria under optimum conditions is an absolute for future biomedicine with corals. According to Campana, et al. [117] about then $1000 \mathrm{~kg}$ of Scleractinian (Goniopora or Porites) coral skeleton would be needed worldwide every year. Coral Cultivation in Captivity. Growing corals, and controlling the skeletal construction, shape, morphology, and architecture, is an exciting possibility to reformat and sculpt new skeletal structures.

In particular, the shapes, arrangements, and sizes of micrometric, macrometric, and nanometric structural elements and voids between them can all be altered. Corals have an intrinsic phenotypic plasticity during their lifetime, which enables them to change according to variations in surrounding light, nutrients, and water flows. The nutrient composition of the culture media is one variable that can strongly influence the structure and architecture of the skeleton. Biomimetic Generation of Coral Skeletons. Methods in biomimetic materials chemistry have demonstrated the possibility of creating complex inorganic forms. Better propagation techniques to accelerate growth and development of coral exoskeletons, better cultivation regimes to increase biomass, new techniques to extract usable amounts of organic components for artificial coral biomineralization and bone induction are needed to exploit the biomimetic materials chemistry and forge coral skeletal mimics with specific regenerative interactions.

\section{Coral as a Carbon Dioxide Scavenger}

Rainwater dissolves atmospheric carbon dioxide producing carbonic acid. Carbonic acid also reacts with rock through chemical weathering to form bicarbonate ions $\left(\mathrm{HCO}_{3}{ }^{-}\right)$that are carried by groundwater and streams to the ocean. Marine organisms use bicarbonate and the calcium ion $\left(\mathrm{Ca}^{2+}\right)$ in seawater to produce the calcium carbonate $\left(\mathrm{CaCO}_{3}\right)$ that they need to make their shells, skeletons, and spines. A coral reef is one example a coral reef is a huge colony of organisms that use calcium carbonate to build a hard outer skeleton. When marine organisms die, their remains slowly sink and reach the ocean floor. Over time, these organic materials are compressed by their own weight and other sediments, gradually changing into carbonate rock, such as limestone. Biomimicry Stories. Coral polyps are tiny, soft-bodied organisms related to sea anemones and jellyfish. At their base is a hard, protective limestone skeleton called a calicle, which forms the structure of coral reefs. Carbon dioxide created from cellular metabolism in the coral polyp diffuses into a closed space directly above the existing coral skeleton. This $\mathrm{CO}_{2}$ is transformed into a building material for its exoskeleton.

\section{The Stanford Case}

Inspired by this construction process, Stanford's scientist Brent Constanz has developed a way to capture $\mathrm{CO} 2$ and dissolve it in seawater to form calcium carbonate, which has properties suitable for use in construction and could replace Portland cement (which is responsible for more than a ton of $\mathrm{CO} 2$ for every ton of product created). This new technology could reduce the environmental 
impact of construction in a big way by capturing and sequestering $\mathrm{CO}_{2}$ emissions while creating a durable building material. Constanz was appalled to by environmental footprint of the cement industry, so he decided to direct his research as a biomineralization expert towards finding alternatives. Coral's skeleton is made up of calcium carbonate, which can be easily synthesized by dissolving $\mathrm{CO}_{2}$ in seawater to form carbonate and then mixing it with calcium to form a solid. This technology is an amazing example of biomimicry that represents a big win for the environment. Calera is the spin-off company that Constanz created to develop and market his technology. They already have a plant set up in California's Monterrey Bay that takes waste $\mathrm{CO}_{2}$ gas from the local power plant at Moss Landing to create calcium carbonate.

This product can then be used to replace Portland cement. Every ton of cement replacement produced by Calera avoids the release of approximately one ton of carbon dioxide that would otherwise be emitted by the traditional manufacturing of Portland Cement. Blue Planet's Case: Blue Planet's technology uses $\mathrm{CO}_{2}$ as a raw material for making carbonate rocks. The carbonate rocks produced are used in place of natural limestone rock mined from quarries, which is the principal component of concrete. $\mathrm{CO}_{2}$ from flue gas is converted to carbonate $\left(\right.$ or $\mathrm{CO}_{3}$ ) by contacting $\mathrm{CO}_{2}$ containing gas with a waterbased capture solution. Blue Planet's carbonate rocks are used as aggregates in concrete, in highly reflective roofing tiles, and as an alternative to titanium dioxide white pigment. Aggregate in sizes ranging from sand grain to gravel. Blue Planet $\mathrm{CaCO}_{3}$ powder, is $100 \mathrm{x}$ less expensive than $\mathrm{TiO} 2$, also exhibits a higher solar reflectance than $\mathrm{TiO}_{2}$ (96\%). It can be used in food, beverage and cosmetics as a $\mathrm{TiO}_{2}$ replacement or filler. This differentiates the Blue Planet from most $\mathrm{CO}_{2}$ capture methods because the captured $\mathrm{CO}_{2}$ does not require a purification step, which is an energy and capital-intensive process. As a result, the Blue Planet's capture method is extremely efficient, and results in a lower cost than traditional methods of $\mathrm{CO}_{2}$ capture. Each rock particle is coated with Blue Planet's synthetic limestone, forming a carbon-sequestering coating that is $44 \%$ by mass $\mathrm{CO}_{2}$. Genetically Engineered Corals. Recently, some researchers are thinking seriously about how genetic modification could help blunt the climate threat. One is Line Bay, a coral geneticist at (the Australian Institute of Marine Science (AIMS) who is also heading a committee advising the Australian government on how to spend $\$ 70$ million it has committed to research into coral adaptation and restoration. Today, the planet is on course to crack $3^{\circ} \mathrm{C}$ by 2100 . Then there is the added threat of ocean acidification. The sea's absorption of carbon dioxide lowers the $\mathrm{P}^{\mathrm{H}}$ of seawater, making it corrosive to the calcium carbonate shells that corals and many other marine creatures build. The question is whether we could give coral reefs an artificial advantage in the evolutionary race against climate change. Genetically engineering corals to make them better able to withstand heat and resist bleaching is among the possibilities. Currently, the coral products commercially available as bone grafts are composed of corals in their natural form. And coral reefs are exposed to catastrophic situations. According to research by the International Union for Conservation of Nature (IUCN) David et al. [118], one third of the world's coral species are said to be at increased risk of extinction. Thus, there is a need to look for alternatives, and cultured coral can be a suitable option.

\section{Concluding Remarks and Futures Directions}

An ideal bone graft substitute should be osteoconductive, inert, readily available and adaptable in terms of size and shape. It should also be biodegradable and biocompatible, to allow bone ingrowth and provide structural support. Corals pose several of the aforementioned properties. Coral structure is similar to cancellous bone and one of the few xenogeneic materials that can form chemical bonds with bone in vivo. Coral based biomaterial could overcome the drawbacks of autologous bone grafting. The available literature utilizing calcium carbonate grafts for fracture healing is rather limited and our personal series will help fill this gap. Their resorption is unpredictable with some authors reporting full resorption while in other studies the resorption was poor. In our personal series, natural coral implanted into bony tissue is gradually resorbed and replaced by newly formed bone after 3 years [119]. However, Dr. Cirotteau's 20 years of experience, using coral and bone marrow in very poorly vascularized sites (e.g. radius, cubitus) in patients ranging from 30 to 88 years old did not lead to any failure. His observations throughout the years show that a poor vascularization of a site is in no way a contraindication to the grafting of this wonderful biomaterial.

The readers can find some of these cases and others on his site: osteoporosis-surgery.fr. Another thing to take into account with the coral material is the initial mechanical weakness. Once bone ingrowth occurs the mechanical stability improves. It is characteristic that the compressive strength of corals could be as low as $2.62 \mathrm{MPa}$ when the one of bone is between 131 and $283 \mathrm{MPa}$. Even if the abovementioned issues are addressed, corals can be considered a viable solution as a bone graft material only if they are sustainable and with minimal environmental impact [120]. Porites and Goniopora corals that are used for the commercially available products derive from corals of the Pacific and Indian Oceans. These corals are not classed as endangered, however, their overexploitation together with the environmental changes, ocean warming, and acidification could put them at risk. Furthermore, some authors highlighted the negative effect or even complete cessation of the overall calcification that the rising water temperature and acidity have on these corals. In addition, a substantial decrease in the coral reefs has been noted since 1990 and it is expected that approximately 50\% of the reefs will be destroyed by 2030 . These data add to the overall uncertainty when planning to explore the utilization of the corals further. 
Despite all the aforementioned concerns, we believe that some coral derived biomaterials are good void fillers with distinct role in our armamentarium. Their utilization should be performed with prior knowledge of the properties of each different product [121]. The fact that they are inner osteoconductive material, safe from a disease transmission point of view, and the need to incorporate an osteoinductive signal to safeguard the overall success, is an undisputable strength. As far as the coralline hydroxyapatite is concerned, this should be considered as a permanent implant, the effectiveness of the partially converted analogue would require further investigation in terms of their overall effectiveness and properties in clinical applications [122]. Tissue engineering approaches with graft supplementation with different osteogenic cells, bone marrow, platelet rich plasma and a number of growth factors is promising but the ideal combination enhancing the neoangiogenesis and osteogenesis needs further clarification.

Research is ongoing on strategies how to enhance and optimize bone repair strategies. Ongoing research Coralline-derived bone grafts are safe, inert osteoconductive material, which are readily available in Nature [123]. Their highly porous structure is similar to cancellous bone. Raw coralline graft products are brittle, lack mechanical strength and are resorbed by the host fast. The conversion to hydroxyapatite diminishes the resorption of the graft making it a permanent implant [124]. Our current clinical evidence is limited to well-contained voids in dental and maxillofacial surgery. Some authors report good clinical results, yet others reported devastating poor outcomes. Until further clarification and development of new coral-based implants that address the shortcomings of the current materials the utilization of such material should be limited to well contained, well vascularized defects, bearing into consideration the potential permanent nature of this graft material [125-127].

\section{Acknowledgments}

This work was supported by the Natural Sciences and Engineering Research Council of Canada (NSERC) grant funded by the Federal government (No. RGPIN_2016-06784). We would like to gratefully acknowledge the assistance and help of Hinane Boumghar and Hind Khadraoui in formatting this article and the references.

\section{References}

1. Esther MM Van Lieshout, Volker Alt (2014) Bone graft substitutes and bone morphogenetic proteins for osteoporotic fractures: what is the evidence? Injury 47: 43-46.

2. Giannoudis PV, Arts JC, Schmidmaier G, Larsson S (2011) What should be the characteristics of the ideal bone graft substitute? Injury 42: 1-2.

3. Giannoudis PV, Dinopoulos H, Tsiridis E (2005) Bone Substitutes: An Update Injury 36: 20-27.
4. Panteli M, Pountos, I, Jones E, Giannoudis PV (2015) Biological and molecular profile of fracture non-union tissue: current insights. Journal of cellular and molecular medicine19(4): 685-713.

5. Boutin P, Christel P, Dorlot JM, Meunier A, De Roquancourt A, et al. (1988) The use of dense alumina-alumina ceramic combination in total hip replacement. Journal of biomedical materials research 22(12): 1203-1232.

6. Lerouge S, Huk, O, Yahia LH, Sedel L (1996) Characterization of in vivo wear debris from ceramic-ceramic total hip arthroplasties. Journal of Biomedical Materials Research: An Official Journal of The Society for Biomaterials and The Japanese Society for Biomaterials 32(4): 627-633.

7. Lerouge S, Huk O, Yahia LH, Witvoet J, Sedel L (1997) Ceramicceramic and metal-polyethylene total hip replacements: comparison of pseudomembranes after loosening. The Journal of bone and joint surgery. British volume 79(1): 135-139.

8. Catelas I, Huk OL, Petit A, Zukor DJ, Marchand R, et al. (1998) Flow cytometric analysis of macrophage response to ceramic and polyethylene particles: effects of size, concentration and composition. Journal of Biomedical Materials Research: An Official Journal of The Society for Biomaterials. The Japanese Society for Biomaterials and the Australian Society for Biomaterials 41(4): 600-607.

9. Catelas I, Petit A, Zukor DJ, Marchand R, Huk OL (1999) Induction of macrophage apoptosis by ceramic and polyethylene particles in vitro. Biomaterials 20(7): 625-630.

10. Demers C, Hamdy CR, Corsi K, Chellat F, Tabrizian M, et al. (2002) Natural coral exoskeleton as a bone graft substitute: a review. Bio-medical materials and engineering, 12(1):15-35.

11. Petite H (2002) La bio-ingénierie de la régénération osseuse. médecine/ sciences 18(10) 995-1002.

12. Demers CN, Tabrizian M, Petit A, Hamdy RC, Yahia LH (2002) Effect of experimental parameters on the in vitro release kinetics of transforming growth factor $\beta 1$ from coral particles. Journal of Biomedical Materials Research: An Official Journal of The Society for Biomaterials, The Japanese Society for Biomaterials, and The Australian Society for Biomaterials and the Korean Society for Biomaterials 59(3): 403-410.

13. Ehrlich H (2019) Marine biological materials of Invertebrate origin. Cham: Springer

14. Wangpraseurt D, You S, Azam F, Jacucci G, Gaidarenko O, et al. (2020) Bionic 3D printed corals. Nature communications 11(1): 1-8.

15. Mutsenko V, Gryshkov O, Rogulska O, Lode A, Petrenko AY, et al. (2019) Chitinous scaffolds from marine sponges for tissue engineering. In Marine-derived biomaterials for tissue engineering applications pp. 285-307.

16. Tsurkan D, Wysokowski M, Petrenko I, Voronkina A, Khrunyk Y, et al. (2020) Modern scaffolding strategies based on naturally pre-fabricated 3D biomaterials of poriferan origin. Applied Physics A 126(5): 1-9.

17. Gancz A, Zueva Y, Weiss OE, Hendler RM, Minnes R, et al. (2020) Coralline skeleton biomaterial reduces phagocytosis in mouse blood in vitro. Israel Journal of Chemistry 60(5-6): 586-592.

18. Boller ML, Swain TD, Lasker HR (2002) Skeletal morphology and material properties of a fragmenting gorgonian coral. Marine Ecology Progress Series 228: 131-141.

19. Day AGE, Francis WR, Fu K, Pieper IL, Guy O, et al. (2018) Osteogenic potential of human umbilical cord mesenchymal stem cells on coralline hydroxyapatite/calcium carbonate microparticles. Stem cells international.

20. Guillemin G, Patat JL, Fournie J, Chetail M (1987) The use of coral as a bone graft substitute. Journal of biomedical materials research 21(5): 557-567. 
21. Gay CV, Mueller WJ (1974) Carbonic anhydrase and osteoclasts: localization by labeled inhibitor autoradiography. Science 183(4123): 432-434.

22. Gay CV, Schraer H, Faleski EJ, Schraer R (1974) Localization of carbonic anhydrase in avian gastric mucosa, shell gland and bone by immunohistochemistry. Journal of Histochemistry \& Cytochemistry 22(8): 819-825.

23. Tran CT, Gargiulo C, Thao HD, Tuan HM, Filgueira L, et al. (2011) Culture and differentiation of osteoblasts on coral scaffold from human bone marrow mesenchymal stem cells. Cell and tissue banking 12(4): 247 261.

24. Shamsuria O, Fadilah AS, Asiah AB, Rodiah MR, Suzina AH, et al. (2004) In vitro cytotoxicity evaluation of biomaterials on human osteoblast cells CRL-1543; hydroxyapatite, natural coral and polyhydroxybutarate. The Medical journal of Malaysia 59: 174-175.

25. Lean HF, AH Suzina, A Azlina, TP Kannan (2008) Gene expression analysis of osteoblasts seeded in coral scaffold. Journal of biomedical materials research 87(1): 215-221.

26. Miao X, Sun D (2010) Graded/gradient porous biomaterials. Materials 3(1): 26-47.

27. Zhim F, Ayers RA, Moore JJ, Moufarrège R, Yahia LH (2012) Personalized implant for high tibial opening wedge: combination of solid freeform fabrication with combustion synthesis process. Journal of biomaterials applications 27(3): 323-332.

28. Wang Q Wang Q, Wan C (2012) Preparation and evaluation of a biomimetic scaffold with porosity gradients in vitro. Anais da Academia Brasileira de Ciencias 84(1): 9-16.

29. Sobral JM, Caridade SG, Sousa RA, Mano JF, Reis RL (2011) Threedimensional plotted scaffolds with controlled pore size gradients: effect of scaffold geometry on mechanical performance and cell seeding efficiency. Acta biomaterialia 7(3): 1009-1018.

30. Rossi C, Madl P, Foletti A, Mocenni C (2015) Equilibrium and far-from equilibrium states. In D Fels M Cifra, F Scholkmann (Edn), Fields of the Cell pp. 71-94 Research Signpost.

31. Prigogine I (1991) The arrow of time. In C. Rossi, E. Tiezzi (Edn) Ecological Physical Chemistry pp. (1-2) Elsevier.

32. Lotka AJ (1922) Natural selection as a physical principle. Proceedings of the National Academy of Sciences of the United States of America 8(6): 151.

33. Bejan A (1996) Street network theory of organization in nature. Journal of Advanced Transportation 30(2): 85-107.

34. Manneville P (2006) Rayleigh-Bénard convection: thirty years of experimental, theoretical and modeling work. Dynamics of spatiotemporal cellular structures 41-65.

35. Shapiro IM, Adams CS, Freeman T, Srinivas V (2005) Fate of the hypertrophic chondrocyte: microenvironmental perspectives on apoptosis and survival in the epiphyseal growth plate. Birth Defects Research Part C: Embryo Today: Reviews 75(4): 330-339.

36. Roach HI, Aigner T, Kouri JB (2004) Chondroptosis: a variant of apoptotic cell death in chondrocytes? Apoptosis 9(3): 265-277.

37. Newman SA (2012) Physico-genetic determinants in the evolution of development. Science, 338(6104): 217-219.

38. Ingber DE, Mow VC, Butler D, Niklason L, Huard J, et al. (2006) Tissue engineering and developmental biology: going biomimetic. Tissue engineering, 12(12): 3265-3283.

39. Benyus JM (1997) Biomimicry: Innovation inspired by nature (pp. 320). New York: Morrow.
40. Hernandez R, Polizu S, Turenne S, Yahia LH (2002) Characteristics of porous nickel-titanium alloys for medical applications. Bio-medical materials and engineering 12(1): 37-45.

41. Di Luca A, Ostrowska B, Lorenzo-Moldero I, Lepedda A, Swieszkowski W, et al. (2016) Gradients in pore size enhance the osteogenic differentiation of human mesenchymal stromal cells in three-dimensional scaffolds. Scientific reports 6(1): 1-13.

42. Bretcanu O, Samaille C, Boccaccini AR (2008) Simple methods to fabricate Bioglass $\AA$-derived glass-ceramic scaffolds exhibiting porosity gradient. Journal of Materials Science 43(12): 4127-4134.

43. Harley BA, Hastings AZ, Yannas IV, Sannino A (2006) Fabricating tubular scaffolds with a radial pore size gradient by a spinning technique. Biomaterials 27(6): 866-874.

44. Itin VI, Khachin VN, Gyunter VE, Bratchikov AD, Chernov DB (1983) Production of titanium nickelide by self-propagating high-temperature synthesis. Soviet powder metallurgy and metal ceramics 22(3): 156157.

45. Li BY, Rong LJ, Li YY, Gjunter VE (2000) Synthesis of porous Ni-Ti shape-memory alloys by self-propagating high-temperature synthesis: reaction mechanism and anisotropy in pore structure. Acta materialia 48(15): 3895-3904.

46. Merzhanov AG (1996) Combustion processes that synthesize materials. Journal of materials processing technology 56(1-4): 222-241.

47. Li B, Rong L, Li Y (1999) Microstructure and superelasticity of porous NiTi alloy. Science in China Series E: Technological Sciences 42(1): 9499.

48. Parvizi S, Hasannaeimi V, Saebnoori E, Shahrabi T, Sadrnezhaad SK (2012) Fabrication of porous NiTi alloy via powder metallurgy and its mechanical characterization by shear punch method. Russian Journal of Non-Ferrous Metals 53(2): 169-175.

49. Gunther V, Yasenchuk Y, Chekalkin T, Marchenko E, Gunther S, et al. (2019) Formation of pores and amorphous-nanocrystalline phases in porous TiNi alloys made by self-propagating high-temperature synthesis (SHS). Advanced Powder Technology 30(4): 673-680.

50. Rames Langlade G, Daumas MTF, Yahia LH (2001) Alliage intermetallique poreux. Institut National de la Propriété Industrielle. No d'enregistrement national: 0003508, No de publication: 2806421.

51. Thomas KM (2007) Hydrogen adsorption and storage on porous materials. Catalysis today 120(34): 389-398.

52. Daumas MT, Jouin J, Yahia LH (2001) Porous intermetallic alloy. (Patent PCT, WO 01/70436 A1)

53. Hernandez R, Polizu S, Turenne S, Yahia LH (2002) Characteristics of porous nickel-titanium alloys for medical applications. Bio-medical materials and engineering 12(1): 37-45.

54. Assad M, Jarzem P, Leroux MA, Coillard C, Chernyshov AV, et al. (2003) Porous titanium-nickel for intervertebral fusion in a sheep model: Part 1. Histomorphometric and radiological analysis 1. Journal of Biomedical Materials Research Part B: Applied Biomaterials: An Official Journal of The Society for Biomaterials, The Japanese Society for Biomaterials and The Australian Society for Biomaterials and the Korean Society for Biomaterials 64(2): 107-120.

55. Chu CL, Chung CY, Lin PH, Wang SD (2004) Fabrication of porous NiTi shape memory alloy for hard tissue implants by combustion synthesis. Materials Science and Engineering: A 366(1): 114-119.

56. Assad M, Lemieux N, Rivard CH, Yahia LH (1999) Comparative in vitro biocompatibility of nickel-titanium, pure nickel, pure titanium, and stainless steel: genotoxicity and atomic absorption evaluation. Biomedical materials and engineering 9(1): 1-12. 
57. Aihara H, Zider J, Fanton G, Duerig T (2019) Combustion synthesis porous nitinol for biomedical applications. International journal of biomaterials.

58. Ayers R, Simske S, Moore J, Castillo M, Gottoli G (2004) U.S. Patent Application No. 10/621 pp. 752.

59. Ayers RA, Burkes DE, Gottoli G, Yi HC, Zhim F, et al. (2007) Combustion synthesis of porous biomaterials. Journal of Biomedical Materials Research Part A 81(3): 634-643.

60. Hulbert S, Young FA, Mathews RS, Klawitter JJ, Talbert CD, et al. (1970) Potential of ceramic materials as permanently implantable skeletal prostheses. Journal of biomedical materials research 4(3): 433-456.

61. Guillemin G, JL P (1981) Contribution àlétude du devenir d'un fragment de squelette de corail Madréporaire implanté dans la diaphyse des os longs chez le chien.

62. White RA, Weber JN, White EW (1972) Replamineform: a new process for preparing porous ceramic, metal and polymer prosthetic materials. Science 176(4037): 922-924.

63. Chiroff RT, White EW, Weber JN, Roy DM (1975) Tissue ingrowth of replamineform implants. Journal of biomedical materials research 9(4): 29-45.

64. Souyris FO, Pellequer C, Payrot C, Servera C (1985) Coral, a new biomedical material. Experimental and first clinical investigations on Madreporaria. Journal of maxillofacial surgery 13(2): 64-69.

65. Guillemin G, Meunier A, Dallant P, Christel P, Pouliquen JC, et al. (1989) Comparison of coral resorption and bone apposition with two natural corals of different porosities. Journal of biomedical materials research 23(7): 765-779.

66. Patel A, JL P (1980) Colonisation Osseuse Des Materiaux Mineraux.

67. Issahakian S, Ouhayoun JP (1989) Clinical and histological evaluation of a new filling material: natural coral. Journal de parodontologie $8(3)$ : 251-259.

68. Mora F, Ouhayoun JP (1995) Clinical evaluation of natural coral and porous hydroxyapatite implants in periodontal bone lesions: Results of a 1-year follow-up. Journal of clinical periodontology 22(11): 877-884.

69. Roux FX, Brasnu D, Loty B, George B, Guillemin G (1988) Madreporic coral: a new bone graft substitute for cranial surgery. Journal of neurosurgery 69(4): 510-513.

70. Soost F, Reißhauer B, Herrmann A, Neumann HJ (1998) Natürliches korallines Kalziumkarbonat als alternativer Ersatz bei knöchernen Defekten des Schädels. Mund, Kiefer-und Gesichtschirurgie 2(2): 96100.

71. Marchac D, Sandor G (1994) Use of coral granules in the craniofacial skeleton. Journal of Craniofacial Surgery 5(4): 213-217.

72. Kenesi C, Voisin MC, Dhem A, Laburthe Tolra Y (1997) Ostéotomie tibiale d'addition interne calée par un coin corail: Premiers résultats à propos de 38 interventions. Discussion. Réponse d'auteur. Chirurgie (Paris) 122(7): 379-382.

73. Rouvillain JL, Jouannelle A, Delattre 0, Pascal-Mousselard H, Catonne Y (1997) Apropos of a case of chondromyxoid fibroma of the talus. A review of the literature. Revue de chirurgie orthopedique et reparatrice de l'appareil moteur 83(4): 372-377.

74. De Peretti F, Trojani C, Cambas PM, Loubiere R, Argenson C (1996) Coral as support of traumatic articular compression. A prospective study of 23 cases involving the lower limb. Rev Chir Orthop Reparatrice Appar Mot 82(3): 234-240.

75. Pouliquen JC (1989) Coral as a substitute for bone graft in posterior spine fusion in childhood. French J Orthop Surg 3: 272-280.
76. Braye F, Irigaray JL, Jallot E, Oudadesse H, Weber G, et al. (1996) Resorption kinetics of osseous substitute: natural coral and synthetic hydroxyapatite. Biomaterials 17(13): 1345-1350.

77. Chetail M, Fournie J (1969) Boring mechanism in t lapillus (gastropoda, muricidae)-intervention of an enzymatic system in active transport of cations during destruction of $\mathrm{CaCO}_{3}$. In american zoologist 9(4): 1041.

78. Fricain JC, Bareille R, Rouais F, Basse-Cathalinat B, Dupuy B (1998) In vitro dissolution of coral in peritoneal or fibroblast cell cultures. Journal of dental research 77(2): 406-411.

79. Fricain JC, Bareille R, Ulysse F, Dupuy B, Amedee J (1998) Evaluation of proliferation and protein expression of human bone marrow cells cultured on coral crystallized in the aragonite or calcite form. Journal of Biomedical Materials Research: An Official Journal of The Society for Biomaterials. The Japanese Society for Biomaterials and the Australian Society for Biomaterials 42(1): 96-102.

80. Oladeji O Ige, Lasisi E Umoru, Sunday Aribo (2012) Natural Products: A Minefield of Biomaterials. International Scholarly Research Network. ISRN Materials Science.

81. Dressmann H (1892) About bone sealing in case of cavity-shaped defects of the bone. Contribution to Clin Chir 9: 804-810.

82. Nassiri N, Cirotteau Y, Jussmann A (2006) Seringue pour biomatériau. European Patent Office.

83. Burwell RG (1985) The function of bone marrow in the incorporation of a bone graft. Clinical orthopaedics and related research 200: 125-141.

84. Newman MG, Boyne PJ (1971) The effect of calcified bone matrix on the osteogenic potential of hematopoietic marrow. Oral Surgery, Oral Medicine, Oral Pathology 32(3): 506-512.

85. Lindholm TS, Urist MR (1980) A quantitative analysis of new bone formation by induction in compositive grafts of bone marrow and bone matrix. Clinical Orthopaedics and Related Research 150: 288-300.

86. McDavid PT, Boone ME, Kafrawy AH, Mitchell DF (1979) Effect of autogenous marrow and calcitonin on reactions to a ceramic. Journal of dental research 58(5): 1478-1483.

87. Nade S, Armstrong L, McCartney E, Baggaley B 1983) Osteogenesis after bone and bone marrow transplantation. The ability of ceramic materials to sustain osteogenesis from transplanted bone marrow cells: preliminary studies. Clinical orthopaedics and related research 181: 255-263.

88. Belkoff SM, Mathis JM, Deramond H, Jasper LE (2001) An ex vivo biomechanical evaluation of a hydroxyapatite cement for use with kyphoplasty. American journal of neuroradiology 22(6): 1212-1216.

89. Hill RG, Stamboulis A, Law RV, Clifford A, Towler MR, et al. (2004) The influence of strontium substitution in fluorapatite glasses and glassceramics. Journal of Non-Crystalline Solids 336(3): 223-229.

90. Pizanis A, Garcia P, Pohlemann T, Burkhardt M (2012) Balloon tibioplasty: a useful tool for reduction of tibial plateau depression fractures. Journal of orthopaedic trauma 26(7): 88-93.

91. Gradl G, Knobe M, Stoffel M, Prescher A, Dirrichs T, et al. (2013) Biomechanical evaluation of locking plate fixation of proximal humeral fractures augmented with calcium phosphate cement. Journal of orthopaedic trauma 27(7): 399-404.

92. Ng VY, Granger JF, Ellis TJ (2010) Calcium phosphate cement to prevent collapse in avascular necrosis of the femoral head. Medical hypotheses 74(4): 725-726.

93. Wiegand A, Buchalla W, Attin T (2007) Review on fluoride-releasing restorative materials-fluoride release and uptake characteristics, antibacterial activity and influence on caries formation. Dental materials 23(3): 343-362. 
94. Alkhraisat MH, Mariño FT, Rodríguez CR, Jerez LB, Cabarcos EL (2008) Combined effect of strontium and pyrophosphate on the properties of brushite cements. Acta biomaterialia 4(3): 664-670.

95. Poitout DG, Belmouden B, Paris P (2005) Utilisation des lames-plaques 95 dans le traitement des fractures. Fractures du genou 67.

96. Cognet JM, Martinache X, Mathoulin C (2008) Arthroscopic management of intra-articular fractures of the distal radius. Chirurgie de la Main 27(4): 171-179.

97. Cirotteau Y (2001) Behavior of natural coral in a human osteoporotic bone. European Journal of Orthopaedic Surgery \& Traumatology 11(3):149-160.

98. Louisia S, Stromboni M, Meunier A, Sedel L, Petite H (1999) Coral grafting supplemented with bone marrow. The Journal of bone and joint surgery. British volume 81(4): 719-724.

99. Judet R, Judet J (1965) Osteo-periosteal decortication. Principle, technic, indications and results. Memoires. Academie de chirurgie (France) 91(15): 463-470

100. Guillemin G, Hunter SJ, Gay CV (1995) Resorption of natural calcium carbonate by avian osteoclasts in vitro. Cells and Materials 5(2): 5.

101. Triffitt JT (1996) The stem cell of the osteoblast. Principles of bone biology 39-50.

102. Kadiyala S, Jaiswal N, Bruder SP (1997) Culture-expanded, bone marrow-derived mesenchymal stem cells can regenerate a criticalsized segmental bone defect. Tissue engineering 3(2): 173-185.

103. Masquelet AC, Fitoussi F, Begue T, Muller GP (2000) Reconstruction of the long bones by the induced membrane and spongy autograft. In Annales de chirurgie plastique et esthetique 45(3): 346-353.

104. Yukna RA (1994) Clinical evaluation of coralline calcium carbonate as a bone replacement graft material in human periodontal osseous defects. Journal of periodontology 65(2): 177-185.

105. Yukna RA, Yukna CN (1998) A 5-year follow-up of 16 patients treated with coralline calcium carbonate $\left(\right.$ Biocoral $^{\mathrm{TM}}$ ) bone replacement grafts in infrabony defects. Journal of clinical periodontology 25(12): 10361040 .

106. Cirotteau Y (2019) The coral. This jewel of nature. Independently published.

107. Skocaj M, Filipic M, Petkovic J, Novak S (2011) Titanium dioxide in our everyday life; is it safe? Radiology and oncology 45(4): 227.

108. Wong SW, Leung PT, Djurišić AB, Leung KM (2010) Toxicities of nano zinc oxide to five marine organisms: influences of aggregate size and ion solubility. Analytical and bioanalytical chemistry 396(2): 609-618.

109. Maipas S, Nicolopoulou-Stamati P (2015) Sun lotion chemicals as endocrine disruptors. Hormones 14(1): 32-46.

110. Sánchez Quiles, D, Tovar-Sánchez A (2015) Are sunscreens a new environmental risk associated with coastal tourism?. Environment international 83: 158-170.

111. Fabrega J, Tantra R, Amer A, Stolpe B, Tomkins J, et al. (2012) Sequestration of zinc from zinc oxide nanoparticles and life cycle effects in the sediment dweller amphipod Corophium volutator. Environmental science \& technology 46(2): 1128-1135.
112. Sobek A, Bejgarn S, Rudén C, Molander L, Breitholtz M (2013) In the shadow of the Cosmetic Directive-Inconsistencies in EU environmental hazard classification requirements for UV-filters. Science of the total environment 461: 706-711.

113. Manzo S, Miglietta ML, Rametta G, Buono S, Di Francia G (2013) Toxic effects of $\mathrm{ZnO}$ nanoparticles towards marine algae Dunaliella tertiolecta. Science of the Total Environment 445: 371-376.

114. Spisni E, Seo S, Joo SH, Su C (2016) Release and toxicity comparison between industrial-and sunscreen-derived nano-ZnO particles. International journal of environmental science and technology 13(10): 2485-2494.

115. D’Agata A, Fasulo S, Dallas LJ, Fisher AS, Maisano M, et al. (2014) Enhanced toxicity of 'bulk' titanium dioxide compared to 'fresh'and 'aged'nano-TiO2 in marine mussels (Mytilus galloprovincialis). Nanotoxicology 8(5): 549-558.

116. Leal MC, Ferrier Pages C, Petersen D, Osinga R (2014). Coral aquaculture: applying scientific knowledge to ex situ production. Reviews in Aquaculture 6: 1-18.

117. Campana V, Milano GIUSEPPE, Pagano E, Barba M, Cicione C, et al (2014) Bone substitutes in orthopaedic surgery: from basic science to clinical practice. Journal of Materials Science: Materials in Medicine 25(10): 2445-2461.

118. David 0, Gabriel G (2009) Resilience assessment of coral reefs. Rapid assessment protocol for coral reefs, focusing on coral bleaching and thermal stress. IUCN Resilience Science Group Working Paper Series.

119. Bejan A (1996) Street network theory of organization in nature. Journal of Advanced Transportation 30(2): 85-107.

120. Bretcanu O, Samaille C, Boccaccini AR (2008) Simple methods to fabricate Bioglass $($-derived glass-ceramic scaffolds exhibiting porosity gradient. Journal of Materials Science 43(12): 4127-4134.

121. Brookes M, Revell WJ Blood Supply of Bone Scientific Aspects.

122. Buser HR, Balmer ME, Schmid P, Kohler M (2006) Occurrence of UV filters 4-methylbenzylidene camphor and octocrylene in fish from various Swiss rivers with inputs from wastewater treatment plants. Environmental science \& technology 40(5):1427-1431.

123. Charnley J (1964) The bonding of prostheses to bone by cement. The Journal of bone and joint surgery. British volume 46(3): 518-529.

124. Cirotteau Y (1999) Morphological changes in the upper femoral metaphysis in men with osteoporotic disease. Reports of the Académie des Sciences-Series III-Sciences de la Vie 322(5): 401-411.

125. Cirotteau Y (2004) The behavior of natural coral in a context of diaphyseal atrophic pseudarthrosis. European Journal of Orthopaedic Surgery \& Traumatology 14(2): 89-98.

126. Zhou S, Cui Z, Urban, JP (2004) Factors influencing the oxygen concentration gradient from the synovial surface of articular cartilage to the cartilage-bone interface: a modeling study. Arthritis \& Rheumatism 50(12): 3915-3924.

127. Dorlot JM (1992) Long-term effects of alumina components in total hip prostheses. Clinical orthopaedics and related research 282: 47-52. 